\title{
Recent biotechnological advances as potential intervention strategies against COVID-19
}

\author{
Naun Lobo-Galo ${ }^{1}$ Juan-Carlos Gálvez-Ruíz ${ }^{2}$ Ana P. Balderrama-Carmona ${ }^{3}$ - Norma P. Silva-Beltrán ${ }^{4}$ (D) \\ Eduardo Ruiz-Bustos ${ }^{2}$
}

Received: 29 September 2020 / Accepted: 26 December 2020 / Published online: 9 January 2021

(c) King Abdulaziz City for Science and Technology 2021

\begin{abstract}
The emerging SARS-CoV-2 viral disease (COVID-19) has caused a global health alert due to its high rate of infection and mortality in individuals with chronic cardiovascular comorbidities, in addition to generating complex clinical conditions. This has forced the scientific community to explore different strategies that allow combating this viral infection as well as treating life-threatening systemic effect of the infection on the individual. In this work, we have reviewed the most recent scientific evidence to provide a comprehensive panorama regarding the biotechnological strategies that have been proposed to combat this new viral infection. We have focused our analysis on vaccine production, nanotechnology applications, repurposing of know drugs for unrelated pathologies, and the search for bioactive molecules obtained from natural products. The goals include safely use as potential prophylactic or therapeutic treatments, based on in silico and in vivo studies, including clinical trials around the world for the correct and timely diagnosis of the infection. This review aims to highlight the development of new ideas that can decrease the time lines for research output and improve research quality while at the same time, keeping in mind the efficacy and safety aspects of these potential biotechnological strategies.
\end{abstract}

Keywords COVID-19 - Antivirals · Drugs and COVID-19 · Vaccines against COVID-19 · Nanothenology against COVID19. Natural products against COVID-19

\section{Introduction}

In the late 2019, a cluster of patients with atypical pneumonia was diagnosed in Wuhan, China (Zhou et al. 2020a). The etiological agent was isolated and its genome sequenced, which was found to be an emergent zoonotic virus, member of the Coronaviridae family, genetically related, but not a direct descendent, of another emergent coronavirus, the

Norma P. Silva-Beltrán

norma.silva@unison.mx

1 Departamento de Ciencias Químico Biológicas, Universidad Autónoma de Ciudad Juárez, Ciudad Juárez, Chihuahua, Mexico

2 Departamento de Ciencias Químico Biológicas, Universidad de Sonora, Hermosillo, Sonora, Mexico

3 Departamento de Ciencias Químico Biológicas y Agropecuarias, Unidad Regional Sur, Universidad de Sonora, Navojoa, Sonora, Mexico

4 Departamento de Ciencias de la Salud, campus Cajeme, Universidad de Sonora, Ciudad Obregón, Sonora, Mexico severe acute respiratory syndrome coronavirus (SARS-CoV) (Zhou et al. 2020a; Zhu et al. 2020b). The novel emergent virus named SARS-CoV-2 exhibits a rapid human-to-human spreading via the respiratory tract, and is responsible of a syndrome known as Coronavirus disease of 2019 (COVID19) (Mahase 2020a). Since its discovery, COVID-19 has become a pandemic outbreak with more than 72.196 million people tested positive for the virus, which has resulted in more than 1.6 million deaths around the world by mid-December 2020 (CRC 2020). According to information displayed on the World Health Organization (WHO) COVID-19 Dashboard, even in countries where the number of daily cases has dropped (e.g., China, Australia), it is not possible to say that the virus has disappeared since active cases are still reported daily. For instance, in regions such as Europe and North America, and coinciding with the autumn and winter seasons, a dramatic increase in the number of reported cases has forced some countries (e.g. Italy, France, Germany) to tighten sanitary restrictions. However, in countries where the situation has improved (e.g. Chile), broad continuous testing, surveillance and contact tracing are still 
active. The SARS-CoV-2 infection clinical manifestation is complex; varying from asymptomatic or mild symptoms in more than $80 \%$ of carrier individuals, to severe respiratory and systemic distress, including obstructive pneumonia, hypoxia, pro-inflammatory cytokine storm, coagulopathies, neurocardiovascular disorders, and death. The mortality rate range from 1 to $3 \%$ among symptomatic patients, depending on medical infrastructure and early medical intervention (Connors and Levy 2020; Gupta et al. 2020a; Liu et al. 2020a; Marietta et al. 2020; Pelaia et al. 2020; Saha et al. 2020). Disease severity variations among infected patients are associated to the individual susceptibility, mainly determined by the density of the viral cellular receptor, angiotensin-converting enzyme II (ACE2). This is significantly higher in individuals older than 50 years, or patients with chronic neurocardiovascular comorbidities, such as diabetes mellitus, hypertension, and obesity (Gupta et al. 2020a; Lan et al. 2020).

To this day, neither specific prophylactic nor therapeutic treatment, including antiviral drugs or molecules to reduce severe symptoms, are available, given the novelty of SARS$\mathrm{CoV}-2$, and the lack of regulatory-approved treatments for other coronavirus and related diseases. Consequently, and given the need for rapid development of effective chemotherapeutic compounds for COVID-19 treatment, the current approach has been the repurposing of existing drugs used in unrelated pathologies, especially those that lack significant side effects in the past. These repurposed drugs have been explored with the intent to block or inhibit viral infection or to modulate pathological hyperinflammatory responses (Lobo-Galo et al. 2020; Tu et al. 2020). The reapplication of these drugs has been supported by in silico approaches, inhibition of SARS-CoV-2 or related coronavirus infection in tissue culture and animal models, or pharmacological application in SARS-CoV, or unrelated immunopathologies such rheumatoid arthritis, lupus, or bacterial sepsis. In a similar approach, several current reports propose the use of natural substances as complementary prophylactic or therapeutic antiviral against COVID-19 that have demonstrated efficacy against other coronaviruses related with SARS-CoV-2. Another strategy for the systematic fight against the novel COVID-19 pandemic resides in the prevention of infection through immunization of uninfected individuals with effective vaccine to induce protective anti-SARS-CoV-2 immunoresponses and long-lasting memory. In this sense, Nanotechnology and new materials are other open fronts in the prevention, detection and vaccine approach against COVID19 disease. Here, we review the most recent biotechnological advances in this regard and evaluate the most promising therapeutic approaches for the COVID-19 prevention and treatment. At the same time, we introduce some of the conceivable current and future challenges affronting effective therapeutic approach and diagnostics around the world.

\section{Generalities of the SARS-CoV-2 virus and phases of the infection}

Coronaviruses are single-stranded RNA (ssRNA) enveloped viruses with a series of protruding glycoproteins, called spike protein (S) (Zhou et al. 2020a). Infection and replication inside the permissive host cell are illustrated in Fig. 1. Infection of the susceptible cell infection starts with absorption of the virus through its S-protein to the cell surface ACE2 receptor, followed by proteolytic activation of S-protein fusogenic domain by host transmembrane serine protease 2 (TMPRSS-2). Alternatively, the virus can enter the cell by endocytosis and acidification of the endolysosome (Hamming et al. 2004; Lan et al. 2020; Wang et al. 2020). Upon release of viral ssRNA, the 5 ' regions (orf1a and orf1b) of long genome are translated by ribosomes into two large overlapping polyproteins, pp1a and pp1ab, which are then proteolytically processed by two virally encoded proteases, the chymotrypsin-3-like protease $\left(3 \mathrm{CL}^{\mathrm{pro}}\right)$ and the papain-like protease ( $\left.\mathrm{PL}^{\mathrm{pro}}\right)$, resulting in 16 functional non-structural proteins (NSP-1-16) (Dai et al. 2020; Jin et al. 2020). These released viral NSPs are responsible for inactivating host cellular intrinsic antiviral responses and creating the environment for viral replication. The replication complex, an RNA-dependent-RNA polymerase (RdRNApol) formed by NS7/8/12, catalyzes both transcription of structural genes and replication of the viral genome (Hillen et al. 2020). Essential for virus, RdRNApol has emerged as the main antiviral drug target, mainly through broad-spectrum nascent chain-terminator nucleoside analogs. Nonetheless, NSP14-exonuclease provides resistance to the antiviral Ribavirin, by removing it from stalled replicative chain (Agostini et al. 2018). Viral replication takes place in double-membrane organelles, where genome is packaged by nucleoproteins $(\mathrm{N})$ forming a nucleocapsid that exits the cell via the exocytosis pathways, and by budding through the cellular membrane acquiring the lipid envelop and S-glycoproteins (Angelini et al. 2013).

The observed natural history of the clinical infection in humans include two phases, (i) an early 5-7-day post-exposure asymptomatic period, where SARS-CoV-2 infects the upper respiratory epithelium inducing an apparent suppression of inflammatory response by the host, followed by (ii) a pulmonary infection that can result in mild or severe pneumonia. A portion in this later group can advance to (iii) a hyperinflammatory phase ( $>7$ days) that initiates with infection of the alveolar epithelium, which possesses a higher density of ACE2 viral receptor, resulting in an enhanced infection triggering the expression of a wide arrange of pro-inflammatory cytokines (Liu et al. 2020c; Wang et al. 2020). These responses are responsible 
Fig. 1 Replication cycle of SARS-CoV-2. Depicted are binding of virus to host cell and entry, release of ss(+) RNA and translation of viral replication complex precursor and proteolytic processing that yields several non-structural (NS) proteins that interfere with cellular antiviral defenses, generation of membranous vesicles from ER, and formation of the RNA-replication complex that leads to de novo virus assembly and exit of the cells by exocytosis and budding through the membrane, where it obtains both enveloped and membrane associated proteins included viral receptor glycoprotein S

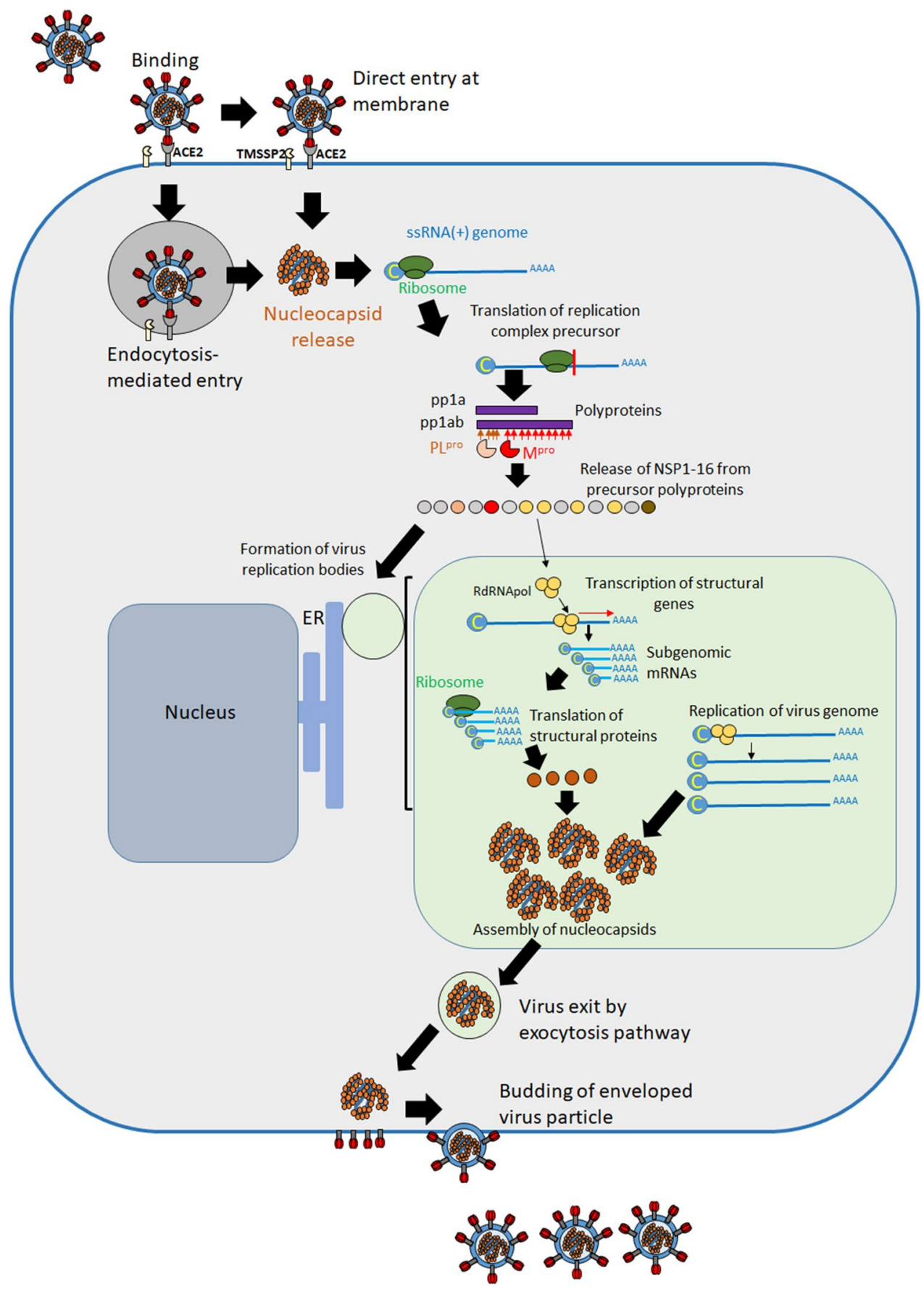

for leukocyte infiltration, proteinaceous-liquid accumulation, and obstruction of the alveoli, and consequently, gas exchange failure and hypoxia (Wang et al. 2020). In addition, a systemic spread of the virus results in additional susceptible, ACE2-expressing, tissue infection, including cardiovascular epithelium, heart, liver, kidney and intestinal linings (Hamming et al. 2004). In this regard, Ziegler et al. (2020) reported that gene expression of ACE2 on the cardiovascular epithelium surface is remarkably enhanced by interferon-mediated responses to the SARS-CoV-2 in the lungs; and consequently, increasing systemic dissemination of the infection to extrapulmonary tissues. The systemic infection, together with enhanced inflammatory responses, is probably responsible of the coagulopathies observed in some individuals (particularly in pulmonary blood cloths observed in autopsies of dead patients), as well as viral septic shock and multi-organ failure that results in high mortality without medical intervention (Connors and Levy 2020; Gupta et al. 2020b; Marietta et al. 2020; Pelaia et al. 2020; Saha 
et al. 2020; Sun et al. 2020b; Ziegler et al. 2020). The pathways that activate inflammatory responses varies significantly among infected patients, however, among the most relevant cytokines associated to severe pathologies are INF- $\gamma$, IL- $1 \beta$, IL-18, while two particular indicators of progression and severity of COVID-19 pathology are TNF- $\alpha$ and IL-6 (Liu et al. 2020a; Sun et al. 2020b). These uncontrolled pro-inflammatory cytokines are presumably the main responsible for the acute respiratory distress (ARDS), cytokine storm syndrome, viral sepsis and multiorgan failure, and subsequent death.

\section{Vaccines against COVID-19: a biotechnological race}

One of the challenges during a novel pandemic is the development of an effective and safe vaccine, to enable a person's immune system to make its own neutralizing antibodies against a pathogen. This vaccine would generate "herd immunity" in a population of susceptible individuals, without risking their life. In this regard, although SARS-CoV-2 was initially perceived as a high transmission rate disease, recent epidemiological seroconversion data in countries that did not apply policies of mandatory population confinement, such as the case of Sweden, indicates that only $7.3 \%$ of its population carries antibodies against SARS-CoV-2 (Habib 2020). Thus, natural effective "heard immunity" of more than $60 \%$ of the Swedish population would require years of continuous spread of the virus, with the associated medical challenges. These data highlight the importance and urgency for an effective vaccine development, which can generate protective immunity in susceptible individuals and reduce the spread of the virus, ending mandatory confinement which has the potential to exacerbate socio-economic problems around the world, particularly in developing countries. Accordingly, research on a prophylactic COVID-19 vaccine has initiated in many companies and academic institutions. The ACTIV (Accelerating COVID-19 Therapeutic Interventions and Vaccines) is a collaborative program that seeks to exchange all the obtained information from the development and testing of developing vaccines, to defeat the new coronavirus and the disease it causes (Corey et al. 2020). A large group of vaccine developers, regulators, scientists, and public health experts who attended the 11-12 February Global Research and Innovation Forum, stated that "We will only halt COVID-19 through solidarity," and "Our shared commitment is to ensure all people have access to all the tools to prevent, detect, treat and defeat COVID-19", according to the World Health Organization (WHO) Director-General (Organization 2020).

Although a vaccine against SARS-CoV was developed, the generation of an anti-SARS-CoV-2 vaccine is on course
(Shereen et al. 2020). Coronaviruses share structures, which include spike (S1 and S2), membrane (M), envelope (E), and nucleocapsid $(\mathrm{N})$ proteins, that could provide relevant antigenic targets (Zhang et al. 2020a). Among these structural proteins, the S-protein contains the determinant structure for virus entry, and thus, antibodies directed against it, particularly the receptor-binding domain (RBD) or the fusogenic domain, should effectively block the virus entrance to susceptible cells. However, the SARS-CoV-2 S-protein amino acid sequences differs from that of SARS-CoV in several regions critical for protective immunity. These include three additional short insertions in the $\mathrm{N}$-terminal domain (NTR, domain $\mathrm{A}$ ) and the $\mathrm{C}$-terminal region (CTR, domains $\mathrm{B}$, $\mathrm{C}$, and $\mathrm{D}$ ), and four out of five key residues changes in the RBD receptor-binding motif (Wu 2020), conforming the S1. On the other hand, the $\mathrm{S} 2$ subunit forms the spike protein branch, and contains two heptad repeats regions (HR1 and HR2) (Robson 2020), similar to other enveloped viruses. The interaction of HR2 located NTR, and HR1 positioned CTR, forms a six-helix bundle structure in which HR2 regions gather into the indentations formed by the trimeric HR1 coiled-coil (Yuan et al. 2004). Existing evidence suggest that the SARS-CoV-2 S-protein binds human ACE2 with higher affinity (10-20-fold) compared to the S-protein of SARS-CoV, which is associated to a more readily transmission form human to human (Jin et al. 2020). Figure 2 shows the herein described mechanism.

Vaccine development is a prolonged process (development, animal model testing and clinical trials, evaluation of safety, regulatory considerations) that normally takes years with high economic costs. Given the urgency in the face of the current pandemic, an accelerated development was proposed to deliver an effective vaccine within 12-18 months (Mahase 2020b); therefore, several previously used and novel platform technologies for rapid and safe vaccine design and manufacturing were chosen. These methodologies consist of a platform-based delivery approach that is adjustable for the modularization of target pathogens antigenic components and enhance their immunogenicity (Hume and Lua 2017). For SARS-CoV-2, several strategies already tested in animal models for prophylactic protection against related MERS and SARS-CoV appear to be the leading candidates. The principal platforms utilized are focused on traditional complete but attenuated virus strategy, complete recombinant antigenic viral proteins as subunit vaccine (mainly the S-protein or specific epitopes from its RBD), or as part of adenoviral vector, and finally novel nucleic acid (DNA, mRNA) delivery technology. In Table 1 are shown the characteristics of the main clinical studies to determine the efficacy, safety, and immunogenicity of a vaccine against COVID-19.

Other studies indicate that nucleic acid vaccines platforms have major advantages, as to rapidly coding for viral 


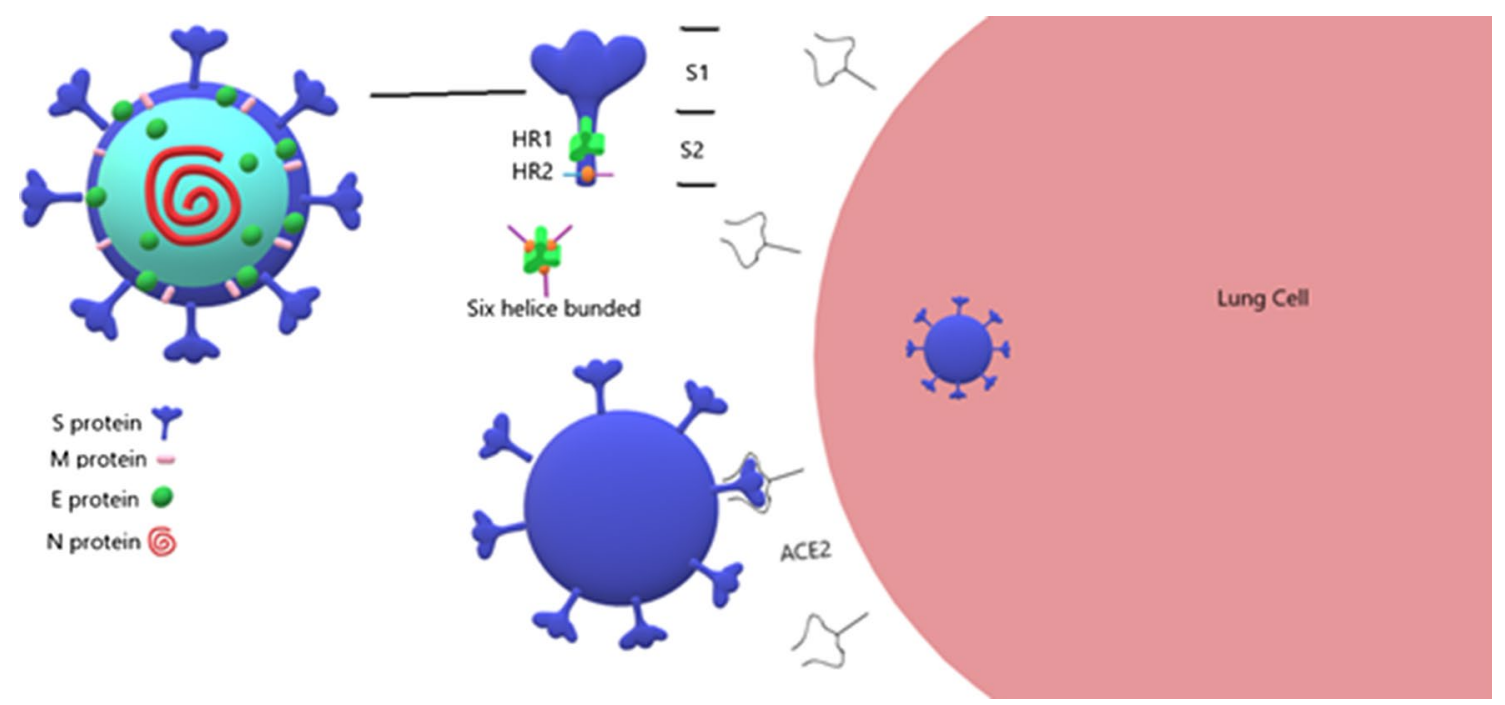

Fig. 2 Schematic structure and entrance of SARS-CoV-2 to human cell through binding SARS-CoV-2 S-protein which includes three additional short insertions conforming the $\mathrm{S} 1$ and $\mathrm{S} 2$ subunits this

proteins expression in the context of human cells, which can induce effective prophylactic host immune responses, albeit, significant research in this output is needed (Prompetchara et al. 2020). In terms of progress, Moderna and CanSino Biologics were the first to begin clinical trials for vaccines against COVID-19 (Cohen 2020), but BioNTech has the next estimated completion (Fig. 3). Medicago and Novavax use a virus-like particle (VLP) platform as scaffolds to present the SARS-CoV-2 S-protein, the second one along with their proprietary adjuvant Matrix-M (Liu et al. 2020b). Countries such as Egypt, Netherlands, Mexico, Greece, Colombia, US, and Australia, are currently developing vaccines based on the Bacillus Calmette-Guerin (BCG), a strategy previously reported to offer broad protection against other respiratory infections. In addition, supporting this repurposing, countries that have a late start of universal BCG policy had seen high mortality, consistent with the idea that BCG protects the vaccinated individuals, and particularly, the elderly population (Hegarty 2020; Miller et al. 2020).

The Brazilian National Regulatory Agency approved Sinovac Biotech Ltd. vaccine generated from attenuated virus, for a phase III clinical study (Raw 2019). Oxford University and Astra Zeneca passed successfully to phase III with chimpanzee adenovirus-vectored vaccine (ChAdOx1 nCoV-19) called AZD1222, which can generate a rapid antibody and $\mathrm{T}$ cell responses against SARS-CoV-2 (Folegatti et al. 2020). Biotech's BNT162 vaccine from mRNA induces positive responses producing antibodies in volunteers (Shin et al. 2020). Although Moderna (mRNA-1273) was the first company set into human trials for a COVID-19 vaccine, in June 25th, 2020, Chinese military approved CanSino Biologics called Ad5 for phase III protocols. Results support last contains the HR1 and HR2 regions which with the connect with the domain regions to form a six-helix bundle structure which allows greater affinity with human ACE2 (Paint 3D)

vaccine effectiveness against a $5 \times 10^{10}$ viral load administered to healthy adults (Zhu et al. 2020a).

Another way to obtain a temporary passive protection is the administration of specific anti SARS-CoV-2 antibodies, derived from COVID-19 convalescent patient's plasma. Therapeutic administration of convalescence sera has so far provided the most effective strategy to treat COVID-19 patients, reducing viral load and preventing significant pathological damage associated with the infection; an observational study of 245 patients with advance disease, suggest that the therapy is safe (Bloch et al. 2020). Moreover, it has been proposed that COVID-19 convalescent sera could be used as a prophylactic measure for in close-contact individuals to prevent respiratory infection, or to treat individuals with early or mild symptoms (Casadevall and Pirofski 2020). Currently, there are clinical trials in different countries developing treatments using convalescent plasma (NCT04333355 and NCT04358783, Mexico; NCT04403477, Bangladesh; NCT04344977, NCT04360278, and NCT04418518, US; NCT04342182, Netherlands; NCT04393727, Italy; NCT04292340, China; NCT04348656, Canada; NCT04425915, India; NCT04352751, Pakistan; NCT04375124, Turkey; NCT04347681, Arabia).

\section{The start of immunizations}

In December 2020, the mRNA-based vaccine developed by Pfizer and BioNTech (BNT162 vaccine) was approved by the Medicines and Health Products Regulatory Agency (MHRA), after showing an efficacy greater than $95 \%$ in phase III. By mid-December, the United States Food and

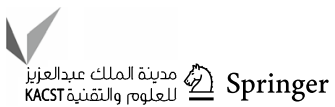




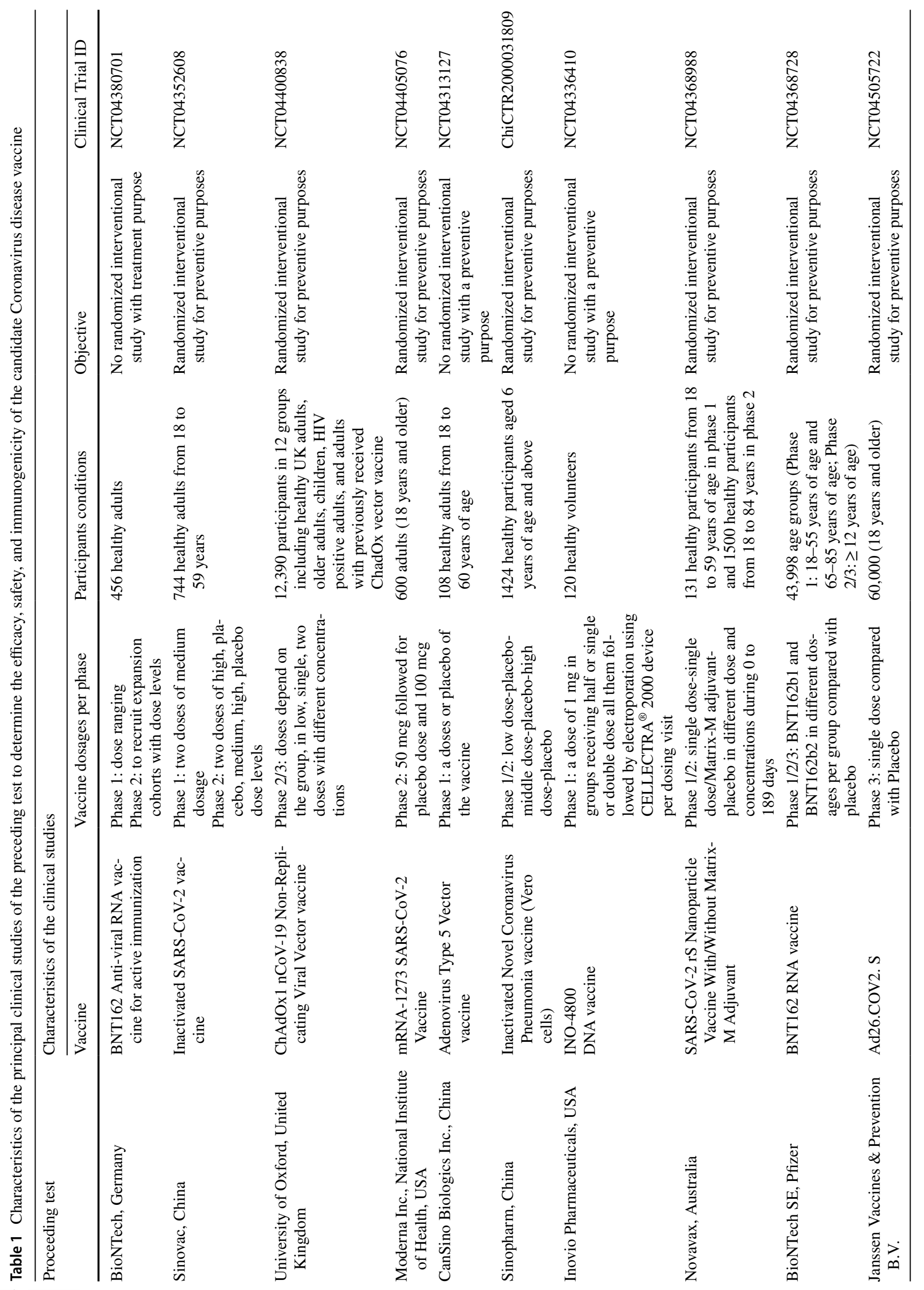




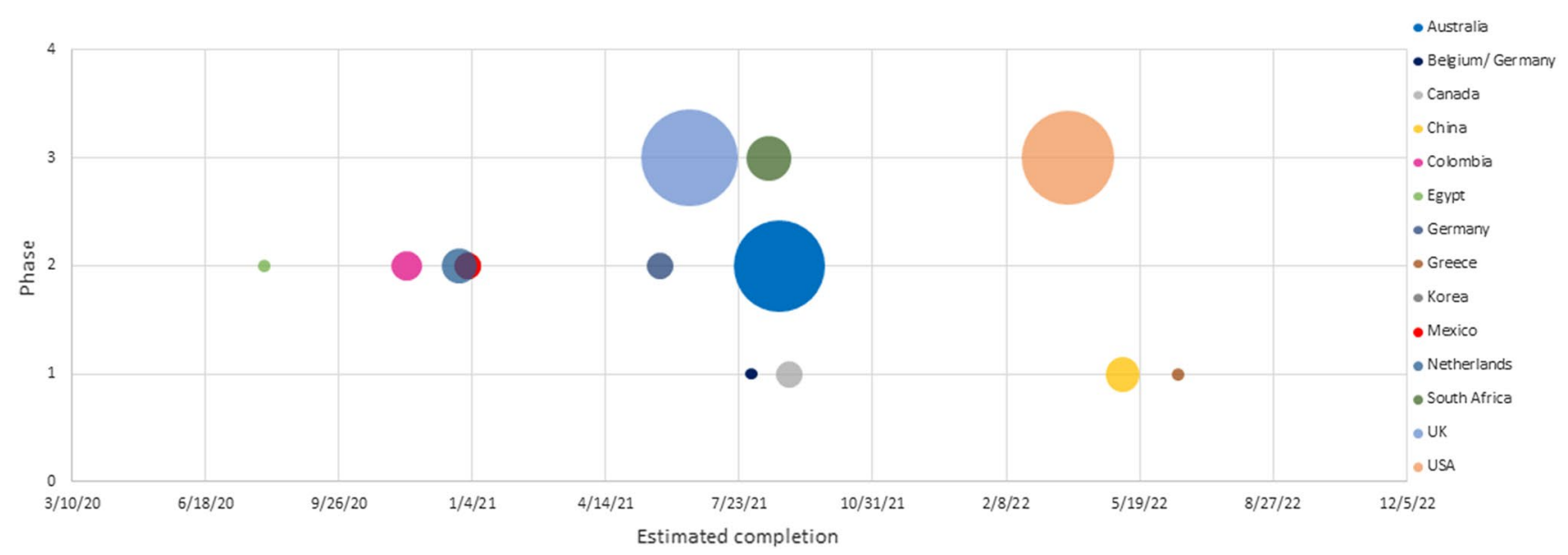

Fig. 3 Country competing in the race for the SARS-CoV-2 vaccine. The $x$-axis shows the estimated record time to finish the clinical tests, and in the axis of the $Y$ are shown the phase they are in of interven-

Drug (FDA) has approved an emergent use authorization of this mRNA vaccine in the United States for individuals older than 16 years, after verification of its safety by a committee of medical experts. Similarly, to this vaccine design, another mRNA vaccine developed by Moderna (mRNA-1273) offers a 94\% efficacy (Cyranoski 2020) and is currently under review by the FDA for licensing and application in immunization of the general population. Although showing very promising efficacy results, these vaccines, but particularly the Pfizer and BioNTech design, requires uninterrupted cold $\left(-70^{\circ} \mathrm{C}\right.$ ) chain requirement (Mahase 2020a, b), which would limit its implementation in less developed countries that lack the necessary infrastructure for transportation and storage. In addition, reports of significant allergic reactions to the Pfizer and BioNTech vaccine by individuals with history of strong food allergies would require further investigation. Alternative vaccines based on Adenovirus which have shown higher than $90 \%$ protective efficacy in phase III, such as those developed by Oxford-Astra Zeneca and Gamaleya Russian Center (Mullard 2020), have advanced significantly and promise less complications in their administrations, and are soon to be submitted for review for implementation.

\section{Nanotechnology as therapeutic strategy against COVID-19}

Since the 1980s, nanotechnology and nanoscience got a boost in its development and applications, offering a number of approaches to cope with different challenges, including the actual COVID-19 pandemic, based on an abundance of engineered materials identifiable by their useful physicochemical properties through versatile chemical functionalization, in addition to the vaccine development (Weiss et al. tional studies of the vaccines. The size of the sphere indicates the number of participants in the research (ClinicalTrials.gov) (Microsoft Excel)

2020). Furthermore, the development of nanomaterials with antimicrobial properties, called nanoantimicrobials, is an ongoing work for the last 16 years (Sportelli et al. 2020).

As example of how Nanotechnology and new materials are used against COVID-19, is LV SMENP DC vaccine, developed by Shenzhen Geno-Immune Medical Institute which modified dendritic cells with lentivirus vectors expressing SARS-CoV-2, engineering a synthetic vaccine including SARS-CoV-2 minigene and immune modulatory genes (Zhang et al. 2020a). In addition, at the University of Washington, another replicon RNA vaccine is under study, formulated with Lipid Inorganic Nanoparticles (LION/ repRNA-CoV2S) to induce rapid immune protection against SARS-CoV-2 infection, which will enter clinical development under the name HDT-301(Erasmus et al. 2020). Another strategy for vaccine development is the administration of gold nanoparticles (Au NP) conjugated with viral antigens, such as the evaluation carried out by Staroverov et al. (2011), achieving higher IFN- $\gamma$ concentrations in mice and rabbits, immunized with Au NPs conjugated with antigens from swine transmissible gastroenteritis virus.

\section{Nanomaterial-based immune approaches}

There are different strategies in which nanomaterials can assist to upregulate the immune system, in an antigen-specific manner, through immune-targeted nanotherapeutics within the vaccination context, including either direct administration of viral antigens, or molecules such as DNA or RNA (Weiss et al. 2020). For instance, it has been suggested that the use of nanoparticles coupled with SARS-CoV-2 $\mathrm{S}$-glycoprotein can induce a precise antibody response against this pathogen, using a mouse model (Nasrollahzadeh et al. 2020), with the advantage that nanoparticles safeguard

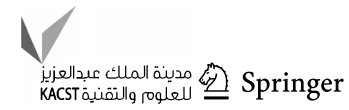


the antigen's native structure, and improves delivery and presentation to the antigen-presenting cells. Another strategy studied for COVID-19 treatment is the employment of Mesenchymal Stem Cells (MSCs) derived exosomes, which have been used for various diseases treatments, such as lung, pancreatic, and breast cancers, Alzheimer's disease, among others, with the advantage that exosomes could prevent cytokines storm, and promote cellular repair (Chauhan et al. 2020; Pinky et al. 2020).

An alternative to prophylactic immunization is the aforementioned therapeutic administration of specific neutralizing antibodies (mainly $\mathrm{IgG}$ ), directed specifically against SARS-CoV-2 RBD of S-protein found in serum from convalescent individuals. Due to the lack of effective antiviral treatments, several hospitals around the world have started to treat severe cases of COVID-19 with transfusion of convalescent plasma $(\mathrm{CP})$.

However, to this date, the overall efficacy of this strategy is not entirely clear, given lack of randomized placebo double-blind studies. Supporting the purposed positive effect of platelet concentrate transfusion, a recent report by Mayo Clinic (Joyner et al. 2020) analyzed the 7-day mortality among 35,370 hospitalized COVID-19 patients receiving this treatment (57\% of which were severe patients and $25 \%$ where in artificial ventilators). This study observed a mortality reduction depending on how early post-diagnosis intervention was applied, as well as the concentration of plasma $\mathrm{IgG}$ in platelet concentrate. Patients receiving platelet concentrate transfusion 3 or 4 days after diagnosis had $8 \%$ mortality, and 11.5 mortality, respectively. Similar reduction of mortality was observed among patients that received plasma with high IgG, compared to those that received a lower IgG titer. Given variations in antibodies concentration present in convalescent patients, an alternative could be the design and development of recombinantly synthesized engineered therapeutic antibodies, commonly known as nanobodies.

Another approach is the use of chimeric nanobodies$\mathrm{Fc}$ (where variable region of nanobody is fused to $\mathrm{Fc}$ of human immunoglobulin). Two recent reports demonstrated that neutralizing nanobodies applied at low concentration (4-18 nM) significantly reduced the number of viral plaque formation upon infection in tissue culture, by effectively binding to SARS-CoV-2 S-protein RBD (Receptor-Binding Domain) and blocking binding to ACE2 receptor (Huo et al. 2020; Schoof et al. 2020). Remarkably, the synthetic nanobodies are small, with potential for aerosolization, and stable to heat, making them a viable alternative for prophylactic or therapeutic anti-COVID-19 applications.

\section{Viral inactivation by nanomaterials}

Different challenges remain in the use of nanomaterials for clinical applications of polymers, oligomers, and small molecules candidates for SARS-CoV-2 clinical application. Cagno et al. (2018) showed that the resulting dilution upon treatment application to the host, results in efficacy loss as the viral compound complex dissociates, a limitation that can be overcome by synthesizing nanoparticles, which can irreversibly inhibit viral infectivity, permanently damaging the virion (Weiss et al. 2020).

Many approaches have been studied as viral inactivators, including cellular nanosponges (Zhang et al. 2020b), humancell-derived membrane structures created as a medical countermeasure against coronavirus. The nanosponges are coated with receptors (such as ACE2-angiotensin-converting enzyme 2-, TMPRSS-2 - transmembrane serine protease 2-and DPP4-dipeptidyl peptidase IV—, expressed on endothelial surfaces) necessary for viral adhesion and cellular entry, which upon contact, inhibit viral interaction with the cellular surface, and hence, cellular invasion. Results reported by Zhang et al. (2020b) show a dose-dependent inhibitory effect on viral adhesion to cultured cells, rendering coronaviruses unable to infect their usual cellular targets. This approach takes into account that although SARS-CoV-2 mainly targets the respiratory tract, it can also affect other organs (including gut, kidney), and even, the vascular system (Weiss et al. 2020), making ACE2 a good candidate for this strategy, due to its wide expression in endothelial tissues.

\section{Nanomaterials as a preventing strategy to prevent SARS-CoV-2 contamination}

SARS-CoV-2 can infect new hosts, not only through direct contact with aerosols from infected persons, but also through contact with surfaces exposed to the pathogen, where the virus has been shown to survive for up to 3 days, depending on the surface type (van Doremalen et al. 2020). For this reason, one of the areas of interest is the prevention of surface viral contamination.

For instance, based on previous work by Leung and Chau (2019), where polyvinyl alcohol (PVA) nanofibers were used to filter ambient aerosols, Leung and Sun (2020) evaluated charged PVDF multilayer nanofiber filters, as a strategy against the airborne novel coronavirus (COVID-19) with monodispersed $\mathrm{NaCl}$ nano-aerosols, obtaining up to $99 \%$ filtration efficiency yields (similar for N98 standards), using PVDF 6-layer charged nanofiber filters in comparison to the $70.6 \%$ efficiency previously obtained. Furthermore, besides its uses for viral detection, graphene has proved to be a good candidate to capture the SARS-CoV-2 virus (Palmieri and Papi 2020).

Although limited, there is work regarding the treatment of Personal Protective Equipment (PPE) with charged metallic (such as $\mathrm{Cu}, \mathrm{Ag}, \mathrm{Fe}, \mathrm{Zn}$ among others) nanoparticles, which seems to result in the release of antiviral agents (i.e., reactive oxygen species). For instance, Ag-coated nanoparticles 
inhibit viral entry in host cells, by means of interactions with cell receptors (Sportelli et al. 2020). In addition, nanotechnology has been applied in food safety studies, exploring the use of nanofibers, nanoemulsions, nanoencapsulated materials among others, by exploiting the advantage of nanomaterials to interact with $60-600 \mathrm{~nm}$ particles. It is thought that nanoscale materials, under controlled release, could be useful to prevent SARS-CoV-2 contamination of both, food products, and packaging materials (Ceylan et al. 2020).

\section{Repurposing of known drugs against COVID-19}

Regarding the COVID-19 pharmacological treatment, until now, only a very limited number of specific anti-SARSCoV-2 compounds (redesigned or developed) are available. However, the most common strategy to identify useful drugs to reduce severe symptoms has been the repurposing existing drugs against unrelated diseases, especially those safely used previously, even if not as antiviral. Since the WHO declared the COVID-19 as pandemic, many studies about the repurposing of known drugs have appeared. The approaches used included in silico, in vitro and in vivo studies, both in cellular culture and animal models, and some of the most promising drugs have undergone clinical trials to test efficacy in reducing viral load, hospitalization time, severity and mortality of the disease.

These anti-SARS-CoV-2 selected drugs, targets several cellular processes or viral enzymes, including virus binding to the receptor or entry into the susceptible cell and release of the genetic material, $\mathrm{M}^{\mathrm{pro}}$ and $\mathrm{PL}^{\text {pro }}$ protease activity, and the most promising so far, inhibitors of the RdRpol, including both nucleosides-analogs and non-nucleoside analog compounds, or immunomodulation of early intrinsic or cellular responses against the infection.

By mid-March, 24 ongoing clinical trials were at clinical phases 2-4. In those trials, the following known drugs were considered: arbidol (umifenovir), bevacizumab, bromhexine, carrimycin, chloroquine, cobicistat, danoprevir, darunavir, favipiravir, fingolimod, human immunoglobulin, hydroxychloroquine, interferons, lopinavir, methylprednisolone, oseltamivir, pirfenidone, remdesivir, ritonavir, thalidomide, vitamin C and xiyanping (Rosa and Santos 2020).

Almost 12,000 known drugs were analyzed in a largescale re-purposing survey, in vitro in Vero E6 cells, from which 30 were identified, including some US Food and Drugs Administration (FDA)-approved drugs, which showed antiviral activity against SARS-CoV-2. From these molecules, the most promising were acitretin, apilimod, astemizole, clofazimine, hanfangchin A, pagoclone, tretinoin, zaleplon GR, AL 3151, AQ-13, DL 28,170, MLN-3897
(AVE-9897), ONO 5334, SL-11128, VBY-825, YH-1238, ZK-93426 and Z LVG CHN2 (Riva et al. 2020).

An initial in vitro study using only FDA-approved drugs showed that amodiaquine, chloroquine, chlorpromazine, hydroxychloroquine, imatinib, and mefloquine have activity against SARS-CoV-2 at non-cytotoxic levels, including the drug $\beta$-D-N4-hydroxycytidine, and its orally bioavailable prodrug $\beta$-D-N4-hydroxycytidine-5'-isopropyl ester (Molnupiravir), were effective against remdesivir-resistant viruses and other zoonotic CoVs (Sheahan et al. 2020; Weston et al. 2020). Currently there are two undergoing phase 3 clinical trials in hospitalized and non-hospitalized adult patients to determinate the efficacy and safety of Molnupiravir (ClinicalTrials.gov 2020).

Considering the possible synergism between drugs with anti-viral activity tested separately (monotherapy), some studies have been conducted. A preliminary clinical study conducted in 80 patients pointed out that a combination of favipiravir with interferon (IFN)- $\alpha$, showed better response and viral clearance than a combination of lopinavir, ritonavir and interferon (IFN)- $\alpha$, on COVID-19 (Cai et al. 2020). Similarly, a phase II trial involving 127 adult patients showed that the combination of ribavirin, interferon beta- $1 \mathrm{~b}$ and lopinavir-ritonavir reduced the viral load, the time for alleviating the symptoms and hospitalization (Hung et al. 2020). However, the combination of drugs not always increases the activity, as it was demonstrated in another study developed in 50 patients where a monotherapy with arbidol was more efficient at eliminating the viral load at day 14 after admission, than a combined therapy with lopinavir-ritonavir (Zhu et al. 2020b). Finally, the trials using the combined therapy with lopinavir-ritonavir in hospitalized patients where discontinued by WHO at early July. It has recently been announced by a Japan Chemical Company, that Favipiravir has met the primary end point in phase III clinical trial conducted in 156 COVID-19-positive patients with non-serious pneumonia, with a shorter time of resolution (Fujifilm Toyama Chemical 2020). Based on this results, the Chilean Ministry of Health has approved the importation of this drug, used in Russia, Turkey and other countries, at request from some Hospitals and the trial is underway. However, is has been pointed out that Favipiravir increase uric acid levels in plasma (ISP, Chile 2020).

A different approach to treat COVID-19 is to focus on the direct elimination of the pathogen, by blocking the virus-host interaction via locking some host proteins used by the virus to interact with them. Those proteins have become the target of known drugs, identifying, in vitro, almost 70 drugs, some of them FDA approved and the rest in clinical or preclinical phase. The latter include clemastine, cloperastine, haloperidol, hydroxychloroquine, progesterone, siramesine, ternatin-4, zotatifin, PB28, PD-144418 and PS3061, which were the most outstanding drugs according 
with such activities, although it is important to underline that PB28 emerged as the most promising drug. However, caution should be taken with the use of cloperastine and clemastine, due to their potential side effects. It was also pointed out that the well-known drug dextromethorphan displayed pro-viral activity (Gordon et al. 2020).

The use of chloroquine for the treatment of COVID19 was in response to an initiative of the State Council of China. In an initial in vitro study, hydroxychloroquine showed better anti-SARS-CoV-2 activity than chloroquine, and some trials conducted in patients reported a reduction in the recovery time, but the evidence was limited (Alia and Grant-Kels 2020). The FDA authorized the emergency use of the chloroquine and hydroxychloroquine drugs by the end of March, however, due to the presence of different adverse events in patients treated with the mentioned drugs, a pharmacovigilance memorandum was emitted by mid-May, as warning, about the adverse event in the setting of COVID19 (Gupta and Malviya 2020). Furthermore, SARS-CoV-2 entry in the pulmonary-derived cell line Calu-3 was not blocked by chloroquine (Hoffmann et al. 2020), suggesting that the virus entry into lung cells can be through activation by TMPRSS-2 and not endocytosis, as it was previously proposed on the Caco-2 intestinal cell line.

A drug that has displayed consistent and effective antiviral activity, in vitro, against animal (including human) coronaviruses, even the SARS-CoV-2, is the experimental, GS-444115 compound or remdesivir. This drug, previously developed to treat Ebola, was authorized by the FDA under emergency use (FDA 2020) to treat COVID-19 in all patients with a severe disease. This drug has been associated to different side effects, including rectal hemorrhages, diarrhea and liver damages. Furthermore, remdesivir is not currently available for oral administration, and thus, intravenous application requires patient's hospitalization (Elmi et al. 2020), complicating large-scale use of remdesivir, potential mutations on the target viral enzyme, RdRpol complex or the associated viral exonuclease, can hinder inhibitory effect by these nucleoside-analog drugs, leading to the emergence of drug-resistant SARS-CoV-2 strains (Shannon et al. 2020).

However, an early trial conducted in China with severe disease (average age 65) showed no statistical differences when remdesivir was intravenously administrated. It should be mentioned that clinical improvement was achieved 5 days earlier, in average (Wang et al. 2020). This recovery time improvement was also observed in a trial conducted in 1063 patients (average age 59), from different countries, where the average recovery time in the group of patients that received intravenous remdesivir was 11 days, compared to 15 days in the control group. In addition, mortality rate among patients receiving remdesivir was $8 \%$, against $11 \%$ in the standard treatment group, which, although not statically significant, the study was terminated early for ethical reasons, due to the occurrence of different-grade adverse events (Beigel et al. 2020). However, in the final report of the same research group, involving 1062 adult patients (average 58 years) in early October, they showed that when remdesivir was used in patients with lower respiratory tract infection, the recovery time was shorter. In addition, they pointed out that remdesivir may have prevented the progression to more severe disease and fewer days with oxygen (Beigel et al. 2020).

By the end of October 2020, remdesivir was granted formal approval by the FDA to be used in patients 12 years, and older, and weight at least $40 \mathrm{~kg}$ (FDA 2020). However, the use of remdesivir remains controversial since an interim WHO Solidarity trial conducted in 11,266 patients $(81 \%$ under 70 year) worldwide, showed that this drug did not improve (or very little) patient's mortality, onset ventilation nor hospitalization time (WHO Solidarity trial consortium 2020).

It is known that one of the main complications found in patients with COVID-19, is the high inflammatory response that causes failure in multiple organs, mainly in the lungs, for which dexamethasone has been included in different treatments, with the aim to improve recovery in patients with acute respiratory distress. In a 2018 study of 277 intensivecare unit patients, but published recently, it was found that early use of dexamethasone helped to reduce both mortality and the number of days for ventilator use. During this trial, the most common adverse event (approximately $70 \%$ of patients) was hyperglycemia (Villar et al. 2020).

The RECOVERY Collaborative Group (Group 2020) reported similar results in a study with 6425 patients (mean $66 \pm 15$ years of age), where an improvement was observed by day 28 of treatment, in patients using mechanical ventilator. They concluded that immunopathological problems dominated the initial stage of the disease. Recently, the NIH suggested in its COVID-19 treatment guidelines the use of dexamethasone, both in hospitalized patients who need mechanical ventilators or oxygen alone, but not in patients who do not need supplemental oxygen, and for those cases where dexamethasone is not available, the NIHpanel suggests the use of prednisone, methylprednisolone or hydrocortisone (Health 2020). Similar conclusions, lower 28-day mortality, were achieved in a prospective meta-analysis using data form 7 different clinical trials where 1703 patients (median age 60 years) with severe disease where treated with methylprednisolone, hydrocortisone or dexamethasone. However, some adverse events occurred (WHO REACT-Working Group 2020).

Artificial intelligence and network medicine have played an interesting role in accelerating repurposing of known drugs against COVID-19. For example, Mefuparib has been proposed by machine learning and statistical analysis, to display a more potent antiviral activity than remdesivir. Similarly, Toremifene has been identified, by network 
analysis, as good treatment for COVID-19 since it could block the ACE2 and spike protein interaction. In addition, some in vitro assays have shown the antiviral activity of this molecule. Using a network-based methodology, it was possible to find a combination of drugs that could have potential activity against COVID-19, such as dactinomycin-sirolimus, melatonin-mercaptopurine, emodin-toremifene and toremifene-melatonin. The latter combination has been tested in a clinical trial in patient with early disease (Zhou et al. 2020b).

\section{Natural products against COVID-19}

Medicinal herbs, as well as bioactive substances that were extracted and purified from various plants, are promising sources for antiviral drugs. It is common for antiviral treatments to have available designs based on natural compound structures. Among the classic examples, we have homoharringtonine and emetine, derived from the Cephalotaxus and Psychotria ipecacuanha plants, respectively, which have anti-herpes virus properties and have effectively inhibited SARS-CoV replication (Hassan 2020; Mani et al. 2020). Notably, almost half of the drugs approved between 1981 and 2014 were derived or mimicked a natural compound (Newman and Cragg 2016).

On the other hand, due to the urgency of effective antiviral treatments against COVID-19, the scientific community has been forced to explore every product that could safely be administered as prophylactic or therapeutic antiviral compounds against SARS-CoV-2 infection. In addition, the study strategies include those carried out not only in vivo with one or more biomolecules together, but also those in silico studies. There are several current reports that propose natural substances against COVID-19, which correlate with previous studies reporting proven efficacy against SARSCoV (Ang et al. 2020; Mani et al. 2020). Likewise, given the current pandemic, the medical society is reusing different antiviral drugs, combining them with biomolecules. As an example, the combination of the drug Tenofovir and Glycyrrhizin (natural compound) has been studied as possible useful combinations against coronavirus infections (Bailly and Vergoten, 2020). In this context, we collected information on herbal formulations and compounds derived and in silico studies from natural products that show therapeutic or prophylactic potential, in addition to guiding and contributing to the successful treatment against SARS-CoV-2.

\section{Effectiveness and care in the administration of herbal formulation against COVID-19}

In the current and real fight for of COVID-19 control, the utilization of herbal formulations as complementary treatments has been an alternative; to control this disease, some natural products of ancient uses and mostly of Chinese origin have been recently evaluated and studied. Most herbal formulations are considered safe due to their long history of use for prevention, treatment and control of various diseases, however, there are reports of toxicity, which can largely be due to misidentification and overdose. In addition, caution should be taken when there is no documentation of long historical use of herbal mixtures (Lutoti et al. 2020).

It is important to consider that COVID-19 generates different clinical effects and depends on the progression of the disease (Luo et al. 2020), so a holistic treatment is necessary to eliminate infection effects, such as the appearance of immune cells detachment, since their presence in blood increases the risk of an excessive immune response, directly leading to cytokine storms (some patients develop severe cardiovascular and kidney complications). In addition, those treatments must maintain intestinal homeostasis and protect the intestinal wall barrier (Luo et al. 2020; Yang et al. 2020). For this reason, formulations or preparations based on medicinal herbs that can inhibit the different effects and stages of the disease have been studied. For example, the study realized by Luo et al. (2020) reports formulations made according to the progression of the disease that can maintain intestinal homeostasis and, inhibit IL-1 $\beta$ production mediated by Toll receptors, and improve the expression of IL-10. The formulations used were: for mild disease stage: Pogostemon Cablin (Blanco), Atractylodes Lancea (Tunb.) Dc., Scutellariae Radix, Chaihu Radix Bupleuri, Forsythiae Fructus; for moderate stage: Gypsum, Atractylodes Lancea (Tunb.) Dc., Polygoni Cuspidati Rhizoma Et Radix, Pogostemon Cablin (Blanco), Verbenae Herb; for severe stage: Ephedra Herba, gypsum, Lepidii Semen Descurainiae Semen, buffalo horn; for critical stage: Panax Ginseng C. A. Mey., Aconiti Lateralis Radix Praeparata; and for recovery stage: Hedysarum Multijugum Maxim., Ophiopogon japonicus (Linn.f.) Ker-Gawl, Panacis Quinquefolii Radix. Furthermore, they show that kaempferol, beta-sitosterol, stigmasterol, quercetin, luteolin, genkwanin, diop, and isorhamnetin participated in three or more disease stages. A clinical study on 54 patients with COVID-19, treated with these herbal mixtures found a favorable response in the recovery and improvement of patients, and suggested the importance of regulating intestinal function and maintaining microenvironmental balance during treatment (Luo et al. 2020). This is possibly because QFP (Qingfei Paidu Decoction) is included within the evaluated treatment, and according to Pan et al. (2020), unreasonable use of this herbal mixture can cause epigastric discomfort, diarrhea and even high blood pressure.

Another formulation studied was Ma Xing Shu Gan Decoction. The basic prescription is composed of the following herb species: $6 \mathrm{~g}$ of Herba ephedrae (MH), $9 \mathrm{~g}$ of Semen

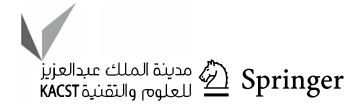


armeniacae amarum (Ku Xing Ren), $24 \mathrm{~g}$ of Gypsum fibrosum (SSG) and $6 \mathrm{~g}$ of Radix glycyrrhizae (GC). The identified active biomolecule was ephedrine glycyrrhizic acid, and the study suggested that it regulates the coagulation system in the inflammatory state, intervening in the inflammatory storm caused by COVID-19 (Yang et al. 2020). The adverse reactions are not yet defined.

On the other hand, the Chinese government included TCM (Traditional Chinese Medicine) as one of the recommended therapeutic options for COVID-19 treatment in the third version of COVID-19 treatment guidelines, which was published on January 23, 2020, included in the 6th edition of the guidelines. The primarily recommended formula was QFP (Qingfei Paidu Decoction) composed of more than 120 biomolecules with important anti-inflammatory effects, identified by UPLC, and detecting as the main active biomolecules to Hesperidin, Astin J, Zingiberoside A, Glycyrrhizic acid, Pogostone, Senkirkine, Ephedrine, Salkosaponin A, Alisol C monoacetate, Dioscin, Irisflorentin, Balcalin, Apigenin, and Synepryne. QFP is effective for patients at all stages, and the total effective rate is $92.09 \%$ and, a daily dose is recommended, once in the morning and in the evening (40 min after a meal), drink warm water, three doses as a course (Pan et al. 2020). The formulation was approved in March 2020 by the Guide for the diagnosis and treatment of pneumonia by COVID-19, from the National Health Commission (NHC) of the People's Republic of China (Ren et al. 2020). Similarly, the formulation was recommended by the Korean guidelines because it increases immunology and reduces inflammation by targeting the lung and spleen, which are the disease pathways of COVID-19. However, the herb Farfarae Flos was removed due to safety and toxicity issues (NIFDS 2020).

\section{Effectiveness and adverse reaction in the administration of bioactive substances against COVID-19}

For the administration of bioactive substances, clinical studies are of vital importance and must be supported by in silico and in vitro studies. Certainly, the FDA has approved a wide range of individual biomolecules that they consider safe, all of them must have timely clinical trials to define their human consumption in the appropriate doses, since even quercetin, which is a promising biomolecule against SARS-CoV-2 has an extensive metabolism in blood plasma leading to low plasma concentrations and although quercetin in a $10 \mathrm{~mL}$ nasal dose of $\sim 76 \mu \mathrm{g}$ has been recommended. The treatment with this biomolecule should be careful in the case of existing lung cancer (Williamson and Keremy 2020).

Alternatively, there are several active principles that have been tested in TCM. Glycyrrhizic acid (GA) is a biomolecule that has been shown to have an effect in silico. Furthermore, it has shown anti-inflammatory effects in humans and antiviral effects against SARS and has been proposed to be effective against COVID-19. GA is considered a drug with a good economic and safety profile. However, at doses of $200 \mathrm{mg}$, it reaches a maximum level in plasma of $80 \mu \mathrm{g} / \mathrm{mL}$, which does not allow the desired biological effect. To increase its effectiveness, structural modifications have been considered, but may result in greater cytotoxicity (Bailly and Vergoten 2020).

Another natural product that has been proposed for the treatment of COVID-19 is propolis, which is a natural product produced by bees, composed mainly by polyphenolic components. Preclinical studies have shown that propolis promotes the immunoregulation of pro-inflammatory cytokines, including the reduction of IL- 6 , IL- 1 beta and TNF- $\alpha$, reducing the risk of cytokine storm syndrome, an important mortality factor in advanced COVID-19 (Barreta et al. 2020). The dosage depends on the standardization, and normally the propolis may have differences due to the raw material, which depends on the ecosystem. However, there is a patent called EPP-AF ${ }^{\circledR}$ that has reproducibility and the clinical data so far support doses of 375-500 mg of propolis/ day (Silveira et al. 2019; Barreta et al. 2020). Propolis has also been shown to be a safe product, but there are still no reports of clinical studies on its effects against COVID-19. However, a clinical trial of Brazilian green propolis extract $\left(\mathrm{EPP}-\mathrm{AF}^{\circledR}\right.$ ) for the treatment of patients with COVID-19 was recently started in Brazil (Barreta et al. 2020).

\section{In silico studies of compound from natural products against COVID-19}

In the need for rapid responses to combat the pandemic, in the last 5 months, many investigations have been published in silico, and as some examples are included in Table 2, which shows some biomolecule studied, as well as the plant of origin and the mechanism possible of against COVID19. The investigations study biomolecules potential, mostly polyphenolic compounds isolated from natural products, which can guide the development of new drugs. Furthermore, these molecular coupling studies have identified biomolecules that inhibit elemental factors for COVID-19 maturation and, as an example, the search for the inhibition of essential viral enzymes helicase, methyltransferase, RNA polymerase, RNA-dependent RNA polymerase (RdRp), 3 cysteine protease similar to chymotrypsin $\left(3 \mathrm{CL}^{\mathrm{pro}}\right)$.

In silico studies on Neoastilbin, a formulation of 14 natural products, as well as Astilbin, made up of 93 natural products, have shown inhibit enzymes such as helicase, methyltransferase, RNA polymerase, and RNA-dependent RNA polymerase (RdRp) in COVID-19 (Naik et al. 2020). In this sense, most virtual screening studies look for different molecular targets, including the inhibition of the 


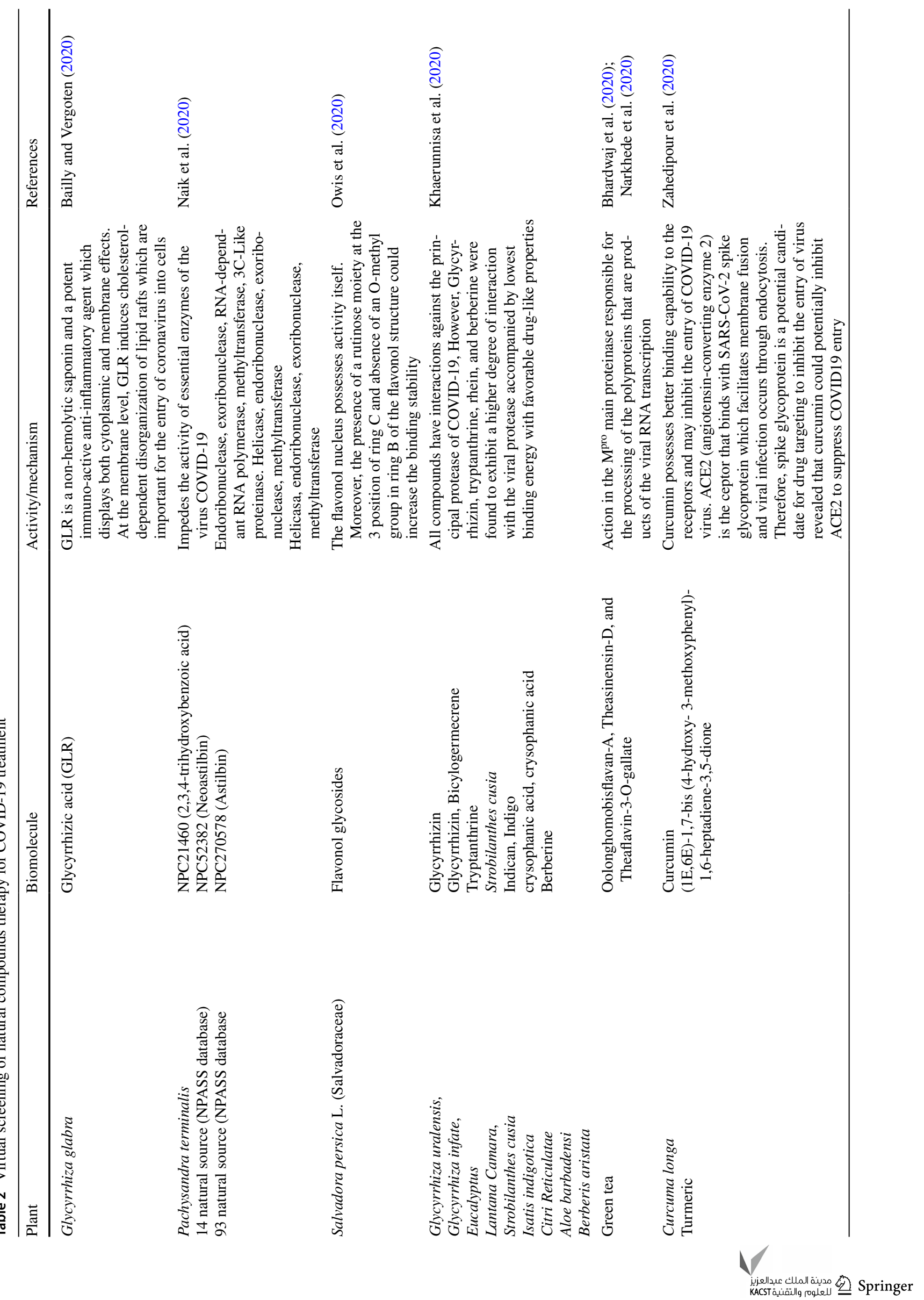



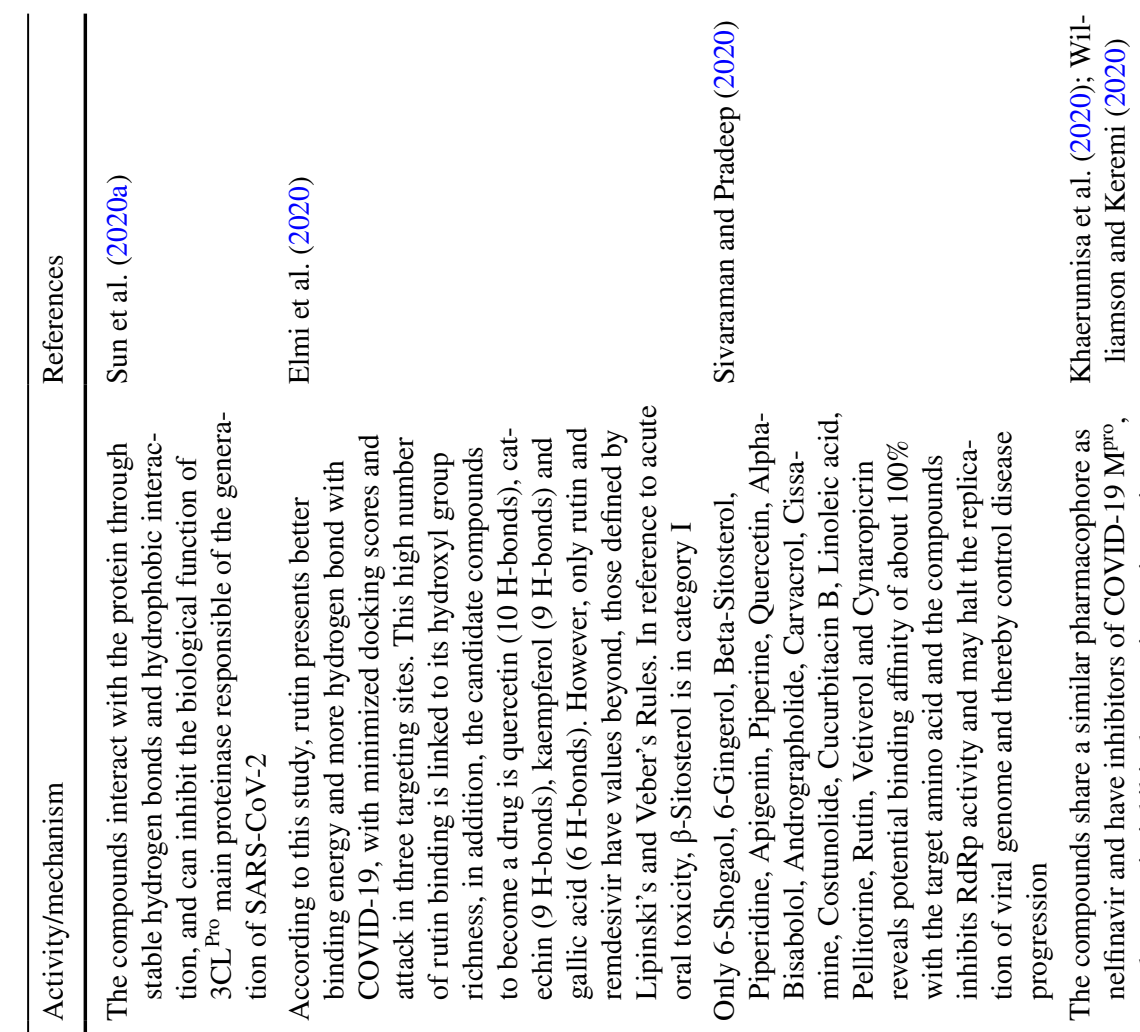

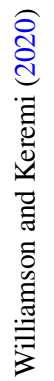
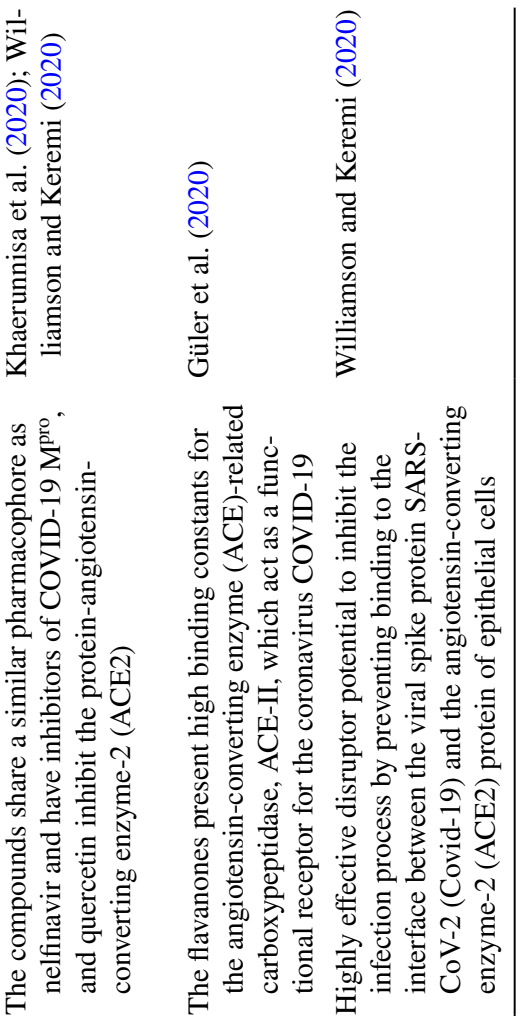

完
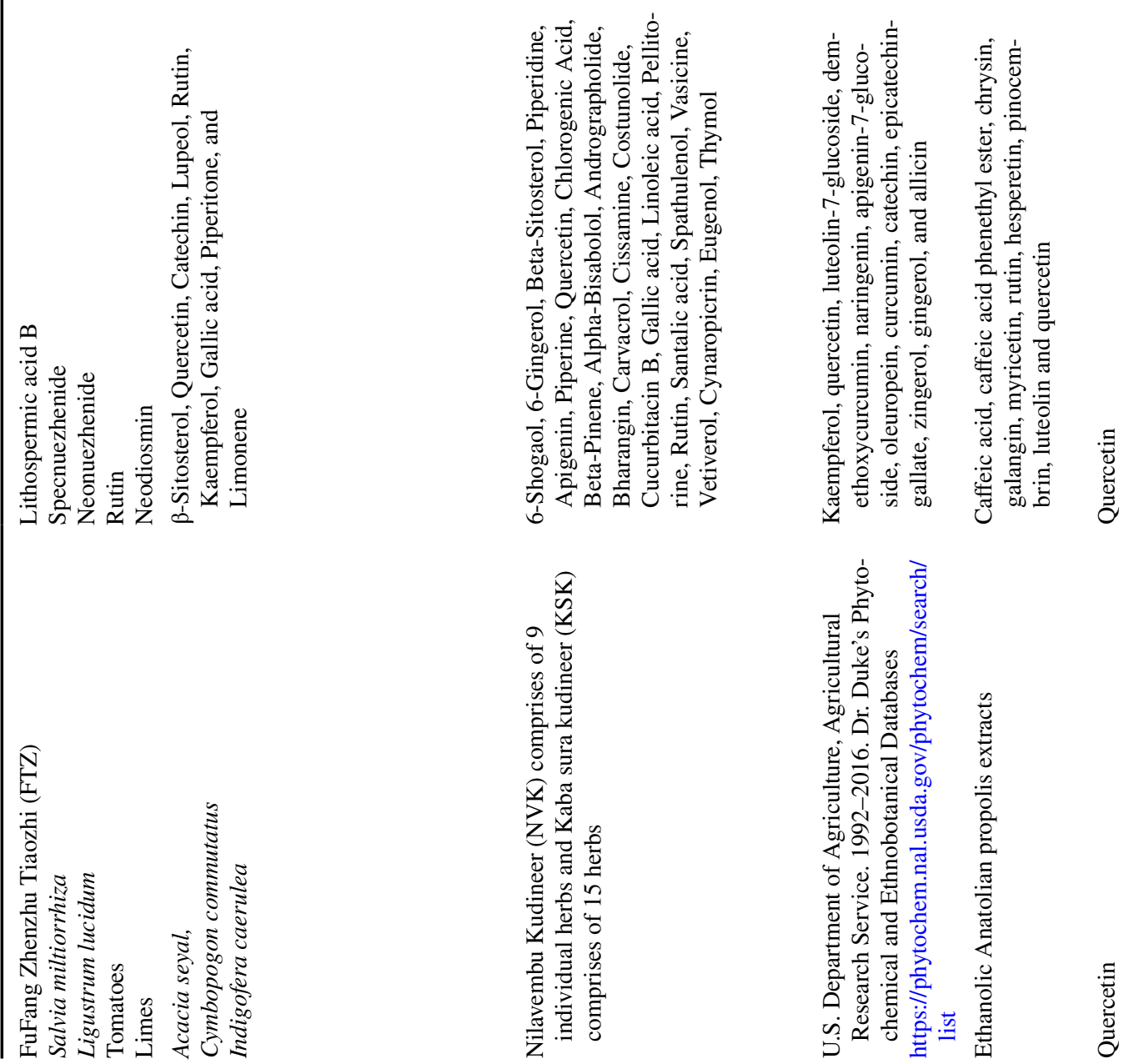

苞 
protein-converting enzyme-angiotensin-2 (ACE2), for example, propolis has also been studied and observed in silico and its flavanones show inhibition mechanisms with high binding constants and high binding affinity to ACE2 and serine protease Transmembrane protease, serine 2 (TMPRSS-2). This mechanism involves overexpression of Serine/threonineprotein kinase (PAK1), which is a kinase that mediates coronavirus-induced lung inflammation, fibrosis, and immune system suppression. In addition, other compounds present in propolis, such as rutin, showed an excellent inhibitory potential, followed by myricetin, phenethyl ester of caffeic acid, hesperetin and pinocembrin (Güler et al. 2020; Barreta et al. 2020). Another biomolecules such as limonin, quercetin, and kaempferol, common compounds in propolis, have been found to inhibit viral RNA-dependent RNA polymerase (RdRp) and spike glycoprotein (SGp), and their effect is acting viral inhibitory potential in the component that adheres to the host cell with high binding energy to viral components from -9 to $-7.1 \mathrm{kcal} / \mathrm{mol}$ (Barreta et al. 2020). Propolis is a relevant therapeutic option, safe, easy to administer orally and readily available as a natural supplement and functional food, and considered GRAS (generally recognized as safe) by the FDA; as well as rutin commonly found in foods like tomatoes and also some in silico studies show, such as rutin, have better binding energy than the hydroxychloroquine and remdesivir drugs against COVID-19 (Adem et al. 2020; Sivaraman and Pradeep 2020). However, although in silico studies have identified the most promising biomolecules against SARS-CoV-2, such as rutin, most researchers conclude that in vitro and in vivo studies are required to verify such antiviral effects. On the other hand, many herbs such as the ones described in this review are not distributed worldwide and in view of the urgency for an effective treatment, complementary therapies are required, and for this reason, today many patients use it to complement western medicine.

\section{Diagnostics and surveillance of COVID-19}

Due to the high person-to-person transmission rate of SARS$\mathrm{CoV}-2$, even from asymptomatic carriers, in addition to the complexity of the progression of the disease among symptomatic individuals, the health sector has been forced to have continuous diagnostic protocols that accurately identify new cases, with the intention of establishing adequate mitigation strategies in an attempt to interrupt or reduce continuous spread. Likewise, early diagnosis of viral infection after symptoms onset, but before complications, and timely antiviral therapeutic intervention is perceived as a critical determinant of the successful outcome of most drugs tested to date (Joyner et al. 2020). On the other hand, surveillance tracking the prevalence of the current and past SARS-CoV-2 infections through seroconversion is extremely helpful at guiding public health policy decisions. In addition, seroconversion identification of active cases and convalescent individuals through population-wide surveillance also provides relevant data for monitoring the success and limitations of prospect prophylactic vaccine-base strategy at reducing susceptibility and transmission, as well as evaluation of promising antiviral drugs with broad-range efficacy and disease progression. Likewise, diagnosis of COVID-19 from upper respiratory track swabs has made use of classical molecular and serological techniques, adapted to detect unique SARS$\mathrm{CoV}-2$ genomic sequence fingerprints through real-time reverse-transcriptase polymerase chain reaction (RT-PCR) amplification, as well as the presence of unique surfaceexposed molecular distinctive antigens, respectively. Early months of the pandemic, active case identification and surveillance was performed by Lab-based molecular RT-PCR tests, using several pair of primers from different sequences of SARS-CoV-2, depending on the country of origin of the test (WHO 2020). One major challenge for these tests was the time for results return; although currently commercially available kits, such as COVID-19 HomeTest Kit from Carbon Health or Roche Cepheid EXpert Xpress, offer results as early as $3 \mathrm{~h}$ (Hogan et al. 2020). Over the last decades, biotechnological advances in molecular biology have made possible the development of rapid tests such as loop-mediated isothermal amplification (LAMP), following an initial RTamplification step. A promising commercial LAMP-based rapid detection test, ID NOWTM COVID Test developed by Abbot's Binaxx, obtained emergency use authorization by the USA-FDA in July given it rapid result returns of as early as $5 \mathrm{~min}$ for positive result and 13 for negative results (Abbot 2020). A recent study by Hogan et al. (2020) showed that ID NOW test has similar sensitivity and specificity of the results as Lab-based RT-PCR tests but only for patients with high viral load on mucus samples; nonetheless, the authors argue that virus could still be transmitted from undetected infected individuals. An alternative approach under study are Aptamers, a pool of oligonucleotides, or even small peptide molecules, and first reported in 1990 (O'Sullivan 2002). Aptamers can be modified and synthesized for different targets, including SARS-CoV-2, they are fast detection methods (results within few seconds), without any previous preparation step of samples (Kumar et al. 2020). Recent work is on course, for the development of a SARS-CoV-2 aptamerbased point of use rapid detection device (https://www.rapid microbiology.com/news/pinpoint39s-low-cost-handheldcovid-19-aptamer-based-diagnostic-device-in-development). Finally, Next-Generation Sequencing (NGS), Micro-array, and lately, a variety of nanotechnology-based methods are rapidly being developed, since nanomaterial-based methods are proven suitable for rapid detection (Rabiee et al. 2020). New generation of biosensors is in the pipeline. Seo et al. (2020) developed a field-effector transistor (FET)-based 
biosensor, for rapid detection of the SARS-CoV-2 virus, taking into consideration that RT-PCR, the primary method for COVID-19 diagnosis, takes at least $3 \mathrm{~h}$ to execute, including viral RNA preparation, step that can affect diagnostic accuracy. Among the advantages of FET-based biosensors, is the ability to measure small amounts of analytes, with high sensitivity and instantaneous measurements.

Efforts to develop high sensitivity and specificity antigen-detection tests include the SARS-CoV-2 anti-Sprotein antibody conjugated to a graphene sheet (Palmieri and Papi 2020) as a sensing area, with no measurable cross-reactivity with antigens from MERS-CoV, successfully detecting the virus in clinical samples, discriminating between patient and normal samples, without any sample preprocessing and high sensitivity. Different $\mathrm{Au}$ NP-based nanomaterials are also candidates for active case detection; Au NPs and quantum dots (QDs) are considered key components for the development of improved novel nanotechnology-based detection systems (Nasrollahzadeh et al. 2020). Among these, is the chiral $\mathrm{Au}$ NP-quantum dot nanocomposites (Ahmed et al. 2017), incorporating viral lipid tails, which proves to promote envelop aggregation and rupture. Another strategy under study are carbon electrodes modified with Au NP (Layqah and Eissa 2019), using a recombinant spike protein SI as a biomarker.

Seroconversion diagnosis of active cases suffers from the low sensitivity (30\%) detection of IgM and IgG antiviral antivirus present in most individual $<7$ days of symptoms onset (Zhao et al. 2020). However, the same study found that $93.1 \%$ of COVID-19 patients demonstrated the presence of detectable level of neutralizing $\operatorname{IgM}$ and $\operatorname{IgG}$ antibodies 11 and 14 days after symptoms onset, respectively. Therefore, although detection of antiSARS-CoV-2 antibodies may not be valuable as an accurate diagnostic tool for active cases, monitoring seroconversion has become relevant for assessment of disease progression (Wang et al. 2020), and infection prevalence surveillance among convalescent individuals in a population. Most serological tests are directed at detecting heterologously expressed viral structural antigens, including nucleocapsid, matrix protein, and mainly S-glycoprotein (Wang et al. 2020). However, it is important to mention that epidemiological surveillance though seroconversion may underestimate the prevalence of SARS-CoV-2 in the population, as a recent report found very low persistence of circulating antiviral antibodies at a detectable concentration following months after virus exposure, especially on individuals who did not require hospitalization (Bruni et al. 2020). Weather re-infection in convalescent individual with low antiviral antibody concentration remains to be determined.

\section{Concluding remarks}

To date, prophylactic and therapeutic intervention on COVID-19 has had limited success. Many of the most promising known drugs repurposed as antiviral to treat SARS-CoV-2 infection were found to have limited antiviral activity, and some produced significant life-threatening cardiovascular problems, which have resulted in suspension of administration. Nucleoside-analogs that target the viral replication complex, specifically viral RdRpol, appear to be the most promising alternative, which in combination with the experimental drug remdesivir show a reduction in hospitalization time and severity of symptoms associated to COVID-19 infection. Biological products, such as plasma from convalescent patients, containing neutralizing antibodies which can block viral entry to cells of susceptible patients, show a reduction in mortality even among severe cases, although effectiveness is still to be determined given the lack of randomized clinical trials. This promising effect of convalescent plasma has been encouraging, as they could predict the effectiveness of vaccines being designed against COVID-19, especially in those platforms that can elicit long-lasting humoral responses, especially antibodies directed against the RBD site of SARS-CoV-2 S-protein, in the general population. Accordingly, recently release results from phase III of two candidate mRNA-based COVID-19 vaccines and several adenovirus-based vaccines have shown higher than $90 \%$ effectiveness and very little side effects among immunized individuals. These promising results have granted emergency use authorization by the FDA of the Pfizer and BioNTech mRNA vaccine. However, requirement of the very-cold transportation and storage of this vaccines threatens to limit administration in countries lacking needed infrastructure. Thus, alternative platforms such as those based on adenovirus are currently under review for use in situations where mRNA vaccines are not possible or contraindicated. Regardless of the success of these current interventions, it is important to maintain surveillance of viral genetic changes that could modify the serotype, as well as drug-targeted viral enzymes, leading to resistant emergent strains. In addition, some of the challenges of this pandemic are the correct and timely diagnosis of the infection. Diagnosis of seroconversion that has been considered important for decision making in mitigation strategies, however, it has been proven that they can underestimate the prevalence, on the other hand, biotechnological advances have made it possible to face these challenges with the generation of molecular techniques, even offer HomeTest with fast and highly sensitive results. In this regard, it will be important to continue investigation on potential application of natural products, especially those 
with few side effects that could inhibit essential viral replication processes and enzymes, that could lead to the design and development of new classes of antiviral drugs.

\section{Compliance with ethical standards}

Conflict of interest The authors have declared no conflict of interest.

\section{References}

Abbott (2020). Abbott Releases ID NOWTM COVID-19 Interim Clinical Study Results from 1,003 People to Provide the Facts on Clinical Performance and to Support Public Health. https://abbot t.mediaroom.com/2020-10-07-Abbott-Releases-ID-NOW-TMCOVID-19-Interim-Clinical-Study-Results-from-1-003-Peopl e-to-Provide-the-Facts-on-Clinical-Performance-and-to-Suppo rt-Public-Health. Accessed 11 Nov 2020.

Adem S, Eyupoglu V, Sarfraz I, Rasul A, Ali M (2020) Identification of potent COVID-19 main protease (mpro) inhibitors from natural polyphenols: An in silico strategy unveils a hope against CORONA. Preprints. https://doi.org/10.20944/preprints202003 .0333.v1

Agostini ML, Andres EL, Sims AC, Graham RL, Sheahan TP, Lu X et al (2018) Coronavirus susceptibility to the antiviral remdesivir (gs-5734) is mediated by the viral polymerase and the proofreading exoribonuclease. MBio. https://doi.org/10.1128/mBio.00221 $-18$

Ahmed SR, Nagy E, Neethirajan S (2017) Self-assembled star-shaped chiroplasmonic gold nanoparticles for ultrasensitive chiroimmunosensor of viruses. RSC Adv 7:40849-40857. https:// doi.org/10.1039/C7RA07175B

Alia E, Grant-Kels JM (2020) Does hydroxychloroquine combat COVID-19? A timeline of evidence. J Am Acad Dermatol 83(1):e33-e34. https://doi.org/10.1016/j.jaad.2020.04.031

Ang L, Lee HW, Choi JY, Zhang J, Lee MS (2020) Herbal medicine and pattern identification for treating COVID-19: a rapid review of guidelines. Integr Med Res. https://doi.org/10.1016/j. imr.2020.100407

Angelini MM, Akhlaghpour M, Neuman BW, Buchmeier MJ (2013) Severe acute respiratory syndrome coronavirus nonstructural proteins 3, 4, and 6 induce double-membrane vesicles. MBio. https://doi.org/10.1128/mBio.00524-13

Bailly C, Vergoten G (2020) Glycyrrhizin: an alternative drug for the treatment of COVID-19 infection and the associated respiratory syndrome? Pharmacol Therapeut. https://doi.org/10.1016/j. pharmthera.2020.107618

Beigel JH, Tomashek KM, Dodd LE, Mehta AK, Zingman BS, Kalil AC, Kline S (2020) Remdesivir for the treatment of covid19-preliminary report. N Engl J Med. https://doi.org/10.1056/ NEJMoa200776

Berretta AP, Duarte-Silveira MA, Cóndor-Capcha JM, De Jong D (2020) Propolis and its potential against SARS-CoV-2 infection mechanisms and COVID-19 disease: Running title: propolis against SARS-CoV-2 infection and COVID-19. Biomed Pharmacother. https://doi.org/10.1016/j.biopha.2020.110622

Bhardwaj VK, Singh R, Sharma J, Rajendran V, Purohit R, Kumar S (2020) Identification of bioactive molecules from tea plant as SARS-CoV-2 main protease inhibitors. J Biom Struct Dyn. https ://doi.org/10.1080/07391102.2020.1766572

Bloch EM, Shoham S, Casadevall A, Sachais BS, Shaz B, Winters JL, Henderson JP (2020) Deployment of convalescent plasma for the prevention and treatment of COVID-19. J Clin Invest 130(6):2757-2765. https://doi.org/10.1172/JCI138745

Bruni M, Cecatiello V, Diaz-Basabe A, Lattanzi G, Mileti E, Monzani S, Pirovano L, Rizzelli F, Visintin C, Bonizzi G, Giani M, Lavitrano M, Faravelli S, Forneris F, Caprioli F, Pelicci PG, Natoli G, Pasqualato S, Mapelli M, Facciotti F (2020) Persistence of anti-SARS-CoV-2 antibodies in non-hospitalized COVID-19 convalescent health care workers. J Clin Med 9(10):3188. https://doi.org/10.3390/jcm9103188

Cai Q, Yang M, Liu D, Chen J, Shu D, Xia J, Yang Y (2020) Experimental treatment with favipiravir for COVID-19: an openlabel control study. Engineering. https://doi.org/10.1016/j. eng.2020.03.007

Cagno V, Andreozzi P, D’Alicarnasso M, Jacob Silva P, Mueller M, Galloux M, Le Goffic R, Jones ST, Vallino M, Hodek J, Weber J, Sen S, Janeček ER, Bekdemir A, Sanavio B, Martinelli C, Donalisio M, Rameix Welti MA, Eleouet JF, Han Y, Kaiser L, Vukovic L, Tapparel C, Král P, Krol S, Lembo D, Stellacci F (2018) Broad-spectrum non-toxic antiviral nanoparticles with a virucidal inhibition mechanism. Nat Mater. https://doi. org/10.1038/nmat5053

Casadevall A, Pirofski L (2020) The convalescent sera option for containing COVID-19. J Clin Invest. https://doi.org/10.1172/ JCI138003

Ceylan Z, Meral R, Cetinkaya T (2020) Relevance of SARS-CoV-2 in food safety and food hygiene: potential preventive measures, suggestions and nanotechnological approaches. VirusDis 31(2):154-160. https://doi.org/10.1007/s13337-020-00611-0

Chauhan G, Madou MJ, Kalra S, Chopra V, Ghosh D, MartinezChapa SO (2020) Nanotechnology for COVID-19: therapeutics and vaccine research. ACS Nano 14(7):7760-7782. https://doi. org/10.1021/acsnano.0c04006

ClinicalTrials.Gov. (2020), https://clinicaltrials.gov/ct2/ results?term $=$ Molnu piravir\&cond $=$ covid $-19 \&$ age $\mathrm{v}=\& \mathrm{gndr}=\&$ type $=\& \mathrm{rs} l \mathrm{t}=\&$ phase $=2 \&$ Search $=$ Apply . Accessed 7 Nov 2020

CRC, Johns Hopkins Coronavirus Resource Center. (2020). Coronavirus COVID-19 global cases by center for systems science and engineering (csse) at Johns Hopkins university 2020. https ://coronavirus.jhu.edu/map. Accessed 16 Dec 2020

Cohen J (2020) Vaccine designers take first shots at COVID-19: American Association for the Advancement of Science. Science 368:14-16

Connors JM, Levy JH (2020) COVID-19 and its implications for thrombosis and anticoagulation. Blood J Am Soc Hematol 135(23):2033-2040. https://doi.org/10.1182/blood.20200 06000

Corey L, Mascola JR, Fauci AS, Collins FS (2020) A strategic approach to COVID-19 vaccine R\&D: a public-private partnership and platform for harmonized clinical trials aims to accelerate licensure and distribution. Science. https://doi.org/10.1126/ science.abc5312

Cyranoski D (2020) Why emergency COVID-vaccine approvals pose a dilemma for scientists. Nature 588(7836):18-19. https://doi. org/10.1038/d41586-020-03219-y

Dai W, Zhang B, Jiang X-M, Su H, Li J, Zhao Y, Liu F (2020) Structure-based design of antiviral drug candidates targeting the SARS-CoV-2 main protease. Science 368(6497):1331-1335. https://doi.org/10.1126/science.abb4489

Elmi A, Sayem Sal J, Ahmed M, Mohamed F (2020) Natural compounds from Djiboutian medicinal plants as inhibitors of COVID-19 by in silico investigations. Preprint ChemRxiv. https ://doi.org/10.26434/chemrxiv.12325844.v1 (Preprint)

Erasmus JH, Khandhar AP, O'Connor MA, Walls AC, Hemann EA, Murapa P, Lewis TB (2020) An alphavirus-derived replicon RNA vaccine induces SARS-CoV-2 neutralizing antibody and

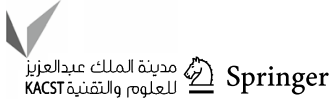


$\mathrm{t}$ cell responses in mice and nonhuman primates. Sci Transl Med. https://doi.org/10.1126/scitranslmed.abc9396

FDA. Food and Drug Administration (2020) FDA's approval of Veklury (remdesivir) for the treatment of COVID-19-the science of safety and effectiveness. https://www.fda.gov/drugs/ drug-safety-and-availability/fdas-approval-veklury-remde sivir-treatment-covid-19-science-safety-and-effectiveness. Accessed 7 Nov 2020

Folegatti PM, Ewer KJ, Aley PK, Angus B, Becker S, Belij-Rammerstorfer S, Clutterbuck EA (2020) Safety and immunogenicity of the ChAdOx1 COVID-19 vaccine against SARS-CoV-2: a preliminary report of a phase $1 / 2$, single-blind, randomised controlled trial. Lancet. https://doi.org/10.1016/S0140 $-6736(20) 31604-4$

Fujifilm Toyama Chemical, 2020, Anti-influenza drug Avigan ${ }^{\circledR}$ Tablet Meets Primary Endpoint in Phase III Clinical Trial in Japan for COVID-19 patients https://www.fujifilm.com/jp/en/news/ hq/5451?_ga=2.24007737.265461932.1604799738-58384 1863.1604176332. Accessed 7 Nov 2020

Gordon D, Jang MG, Jang GM, Bouhaddou M (2020) A SARS-CoV2-human protein-protein interaction map reveals drug targets and potential drug-repurposing. BioXriv. https://doi.org/10.1038/ s41586-020-2286-9

Group RC (2020) Dexamethasone in hospitalized patients with Covid19-preliminary report. N Engl J Med. https://doi.org/10.1056/ NEJMoa2021436

Güler HI, Tatar G, Yildiz O, Belduz AO, Kolayli S (2020) Investigation of potential inhibitor properties of ethanolic propolis extracts against ACE-ii receptors for COVID-19 treatment by molecular docking study. ScienceOpen Preprints. https://doi.org/10.14293 /S2199-1006.1.SOR-.PP5BWN4.v1

Gupta A, Madhavan MV, Sehgal K, Nair N, Mahajan S, Sehrawat TS, Wan EY (2020a) Extrapulmonary manifestations of COVID19. Nat Med 26(7):1017-1032. https://doi.org/10.1038/s4159 1-020-0968-3

Gupta A, Malviya A (2020) Chloroquine and hydroxychloroquine for COVID-19: time to close the chapter. Postgrad Med J. https:// doi.org/10.1136/postgradmedj-2020-138585

Gupta S, Krishnakumar V, Sharma Y, Dinda AK, Mohanty S (2020b) Mesenchymal stem cell derived exosomes: a nano platform for therapeutics and drug delivery in combating COVID-19. Stem cell Rev Rep. https://doi.org/10.1007/s12015-020-10002-z

Habib H (2020) Has Sweden's controversial COVID-19 strategy been successful? BMJ. https://doi.org/10.1136/bmj.m2376

Hamming I, Timens W, Bulthuis M, Lely AT, Navis GJ, Van Goor H (2004) Tissue distribution of ACE2 protein, the functional receptor for SARS coronavirus. A first step in understanding SARS pathogenesis. J Pathol 203(2):631-637. https://doi.org/10.1002/ path. 1570

Hassan ST (2020) Shedding light on the effect of natural anti-herpesvirus alkaloids on SARS-CoV-2: a treatment option for COVID-19: multidisciplinary Digital Publishing Institute. Viruses 12(4):476. https://doi.org/10.3390/v12040476

Health N.I.o. (2020). COVID-19 treatment guidelines panel. Coronavirus disease 2019 (covid-19) treatment guidelines. Guidelines website. https://www.covid19treatmentguidelines.nih.gov/. Accessed 11 Nov 2020

Hegarty P (2020) BCG vaccination may be protective against COVID19. MedRxiv. https://doi.org/10.13140/RG.2.2.35948.10880

Hillen HS, Kokic G, Farnung L, Dienemann C, Tegunov D, Cramer P (2020) Structure of replicating SARS-CoV-2 polymerase. bioRxiv. https://doi.org/10.1038/s41586-020-2368-8

Hoffmann M, Mösbauer K, Hofmann-Winkler H, Kaul A, KleineWeber H, Krüger N, Pöhlmann S (2020) Chloroquine does not inhibit infection of human lung cells with SARS-CoV-2. Nature. https://doi.org/10.1038/s41586-020-2575-3
Hogan CA, Garamani N, Lee AS, Tung JK, Sahoo MK, Huang C, Stevens B, Zehnder J, Pinsky BA (2020) Comparison of the accula SARS-CoV-2 test with a laboratory-developed assay for detection of SARS-CoV-2 RNA in clinical nasopharyngeal specimens. J Clin Microbiol 58(8):e01072-e1120. https://doi.org/10.1128/ JCM.01072-20

Hume HKC, Lua LH (2017) Platform technologies for modern vaccine manufacturing. Vaccine 35(35):4480-4485. https://doi. org/10.1016/j.vaccine.2017.02.069

Hung IF-N, Lung K-C, Tso EY-K, Liu R, Chung TW-H, Chu M-Y, Tam AR (2020) Triple combination of interferon beta-1b, lopinavir-ritonavir, and ribavirin in the treatment of patients admitted to hospital with COVID-19: an open-label, randomised, phase 2 trial. Lancet 395(10238):1695-1704. https://doi.org/10.1016/ S0140-6736(20)31042-4

Huo J, Le Bas A, Ruza RR, Duyvesteyn HM, Mikolajek H, Malinauskas T, Ward PN (2020) Neutralizing nanobodies bind SarsCoV-2 spike RBD and block interaction with ACE2. Nat Struct Mol Biol. https://doi.org/10.1038/s41594-020-0469-6

ISP, Instituto de Salud Pública, Ministerio de Salud, Chile, 2020, ISP autoriza solicitud de importación del medicamento Avifavir para su uso controlado. http://www.ispch.cl/noticia/30300. Accessed 7 Nov 2020

Jin Y, Yang H, Ji W, Wu W, Chen S, Zhang W, Duan G (2020) Virology, epidemiology, pathogenesis, and control of COVID-19. Viruses 12(4):372. https://doi.org/10.3390/v12040372

Joyner MJ, Senefeld JW, Klassen SA, Mills JR, Johnson PW, Theel ES, Lesser ER (2020) Effect of convalescent plasma on mortality among hospitalized patients with COVID-19: initial three-month experience. medRxiv. https://doi.org/10.1101/2020.08.12.20169 359

Khaerunnisa S, Kurniawan H, Awaluddin R, Suhartati S, Soetjipto S (2020) Potential inhibitor of COVID-19 main protease (mpro) from several medicinal plant compounds by molecular docking study. Prepr. https://doi.org/10.20944/preprints202003.0226.v1

Kumar R, Nagpal S, Kaushik S, Mendiratta S (2020) COVID-19 diagnostic approaches: different roads to the same destination. Virus Dis 31(2):97-105. https://doi.org/10.1007/s13337-020-00599-7

Lan J, Ge J, Yu J, Shan S, Zhou H, Fan S, Zhang L (2020) Structure of the SARS-CoV-2 spike receptor-binding domain bound to the ACE2 receptor. Nature 581(7807):215-220. https://doi. org/10.1038/s41586-020-2180-5

Layqah LA, Eissa S (2019) An electrochemical immunosensor for the corona virus associated with the Middle East respiratory syndrome using an array of gold nanoparticle-modified carbon electrodes. Mikrochim Acta 186:224. https://doi.org/10.1007/ s00604-019-3345-5

Leung WWF, Chau YT (2019) Experiments on filtering nano-aerosols from vehicular and atmospheric pollutants under dominant diffusion using nanofiber filter. Sep Purif Tech J 213:186-198. https ://doi.org/10.1016/j.seppur.2020.116887

Leung WW, Sun Q (2020) Charged PVDF multilayer nanofiber filter in filtering simulated airborne novel coronavirus (COVID-19) using ambient nano-aerosols. Sep Purif Technol 245:116887. https:// doi.org/10.1016/j.seppur.2020.116887

Liu B, Li M, Zhou Z, Guan X, Xiang Y (2020a) Can we use interleukin-6 (il-6) blockade for coronavirus disease 2019 (COVID19)-induced cytokine release syndrome (CRS)? J Autoimmun. https://doi.org/10.1016/j.jaut.2020.102452

Liu C, Zhou Q, Li Y, Garner LV, Watkins SP, Carter LJ, Jervey S (2020b) Research and development on therapeutic agents and vaccines for covid-19 and related human coronavirus diseases. ACS Cent Sci. https://doi.org/10.1021/acscentsci.0c00272 (ACS Publications)

Liu K, Fang Y-Y, Deng Y, Liu W, Wang M-F, Ma J-P, Li C-H (2020c) Clinical characteristics of novel coronavirus cases in 
tertiary hospitals in Hubei province. Chin Med J. https://doi. org/10.1097/CM9.0000000000000744

Lobo-Galo N, Terrazas-López M, Martínez-Martínez A, DíazSánchez ÁG (2020) Fda-approved thiol-reacting drugs that potentially bind into the Sars-CoV-2 main protease, essential for viral replication. J Biomol Struct Dyn. https://doi. org/10.1080/07391102.2020.1764393

Luo E, Zhang D, Luo H, Liu B, Zhao K, Zhao Y, Wang Y (2020) Treatment efficacy analysis of traditional Chinese medicine for novel coronavirus pneumonia (COVID-19): an empirical study from Wuhan, Hubei province, China. Chin Med 15:1-13. https ://doi.org/10.1186/s13020-020-00317-x

Lutoti S, Okwany P, Ajayi CO, Oloro J (2020) Formulation and standardization of herbal medicinal products: a review of the formulation considerations, quality control and safety of herbal products. J Pharm Drug Res 3(3):373-381

Mahase E (2020a) Coronavirus: COVID-19 has killed more people than sars and mers combined, despite lower case fatality rate. BMJ. https://doi.org/10.1136/bmj.m641

Mahase E (2020b) Covid-19: what do we know so far about a vaccine? BMJ. https://doi.org/10.1136/bmj.m1679

Mani JS, Johnson JB, Steel JC, Broszczak DA, Neilsen PM, Walsh KB, Naiker M (2020) Natural product-derived phytochemicals as potential agents against coronaviruses: a review. Virus Res. https://doi.org/10.1016/j.virusres.2020.197989

Marietta M, Ageno W, Artoni A, De Candia E, Gresele P, Marchetti M, Tripodi A (2020) COVID-19 and haemostasis: a position paper from Italian society on thrombosis and haemostasis (siset). Blood Transfusion 18(3):167. https://doi. org/10.2450/2020.0083-20

Miller A, Reandelar MJ, Fasciglione K, Roumenova V, Li Y, Otazu GH (2020) Correlation between universal BCG vaccination policy and reduced morbidity and mortality for covid-19: an epidemiological study. MedRxiv. https://doi. org/10.1101/2020.03.24.20042937

Mullard A (2020) COVID-19 vaccines buoy hope. Nat Rev Drug Discov. https://doi.org/10.1038/d41573-020-00215-9

Naik B, Gupta N, Ojha R, Singh S, Prajapati VK, Prusty D (2020) High throughput virtual screening reveals SARS-CoV-2 multi-target binding natural compounds to lead instant therapy for COVID-19 treatment. Int J Biol Macromol. https://doi.org/10.1016/j.ijbio mac.2020.05.184

Narkhede RR, Pise AV, Cheke RS, Shinde SD (2020) Recognition of natural products as potential inhibitors of covid-19 main protease (Mpro): in-silico evidences. Nat Prod Bioprospect. https://doi. org/10.1007/s13659-020-00253-1

Nasrollahzadeh M, Sajjadi M, Soufi GJ, Iravani S, Varma RS (2020) Nanomaterials and nanotechnology-associated innovations against viral infections with a focus on coronaviruses. Nanomaterials 10(6):1072. https://doi.org/10.3390/nano10061072

Newman DJ, Cragg GM (2016) Natural products as sources of new drugs from 1981 to 2014. J Nat Prod 79(3):629-661. https://doi. org/10.1021/acs.jnatprod.5b01055

NIFDS. National Institute of Food and Drug Safety Evaluation. Data collection of the Herbal Medicine Quality Standardization Research Group; 2020. https://www.nifds.go.kr/brd/m184/view. do?seq $=5$. Accessed 6 Nov 2020

WHO (2020) Global leaders unite to ensure everyone everywhere can access new vaccines, tests and treatments for COVID-19 (who newsroom). WHO, Geneva

O'Sullivan CK (2002) Aptasensors-the future of biosensing? Anal Bioanal Chem 372:44-48. https://doi.org/10.1007/s0021 6-001-1189-3

Owis AI, El-Hawary MS, El Amir D, Aly OM, Abdelmohsen UR, Kamel MS (2020) Molecular docking reveals the potential of salvadora persica flavonoids to inhibit covid-19 virus main protease.
RSC Adv 10(33):19570-19575. https://doi.org/10.1039/D0RA0 $3582 \mathrm{C}$

Pan X, Dong L, Yang L, Chen D, Peng C (2020) Potential drugs for the treatment of the novel coronavirus pneumonia (COVID19) in China. Viruses Res. https://doi.org/10.1016/j.virus res.2020.198058

Palmieri V, Papi M (2020) Can graphene take part in the fight against COVID-19? Nano Today 33:100883. https://doi.org/10.1016/j. nantod.2020.100883

Pelaia C, Tinello C, Vatrella A, De Sarro G, Pelaia G (2020) Lung under attack by covid-19-induced cytokine storm: pathogenic mechanisms and therapeutic implications. Ther Adv Resp Dis. https://doi.org/10.1177/1753466620933508

Pinky GS, Krishnakumar V, Sharma Y, Dinda AK, Mohanty S (2020) Mesenchymal stem cell derived exosomes: a nano platform for therapeutics and drug delivery in combating COVID-19. Stem Cell Rev Rep 13:1-11. https://doi.org/10.1007/s12015-02010002-Z

Prompetchara E, Ketloy C, Palaga T (2020) Immune responses in COVID-19 and potential vaccines: lessons learned from SARS and MERS epidemic. Asian Pac J Allergy Immunol 38(1):1-9. https://doi.org/10.12932/AP-200220-0772

Rabiee N, Bagherzadeh M, Ghasemi A, Zare H, Ahmadi S, Fatahi Y, Dinarvand R, Rabiee M, Ramakrishna S, Shokouhimehr M, Varma RS (2020) Point-of-use rapid detection of SARS-CoV-2: nanotechnology-enabled solutions for the COVID-19 pandemic. Int J Mol Sci 21(14):5126. https://doi.org/10.3390/ijms21145126

Raw I (2019) Developing countries can innovate and produce vaccines: the case of Butantan in Brazil vaccines-the history and future. IntechOpen, London

Ren J-1, Zhang A-H, Wang X-J (2020) Traditional Chinese medicine for COVID-19 treatment. Pharmacol Res 155:104743. https:// doi.org/10.1016/j.ctcp.2020.101165

Riva L, Yuan S, Yin X, Martin-Sancho L, Matsunaga N, Burgstaller S, Chang M (2020) A large-scale drug repositioning survey for SARS-CoV-2 antivirals. bioRxiv. https://doi. org/10.1101/2020.04.16.044016

Robson B (2020) Computers and viral diseases. Preliminary bioinformatics studies on the design of a synthetic vaccine and a preventative peptidomimetic antagonist against the SARS-CoV-2 (2019-ncov, COVID-19) coronavirus. Comput Biol Med. https ://doi.org/10.1016/j.compbiomed.2020.103670

Rosa SGV, Santos WC (2020) Clinical trials on drug repositioning for COVID-19 treatment. Rev Panamericana de Salud Pública 44:e40. https://doi.org/10.26633/RPSP.2020.40

Saha A, Sharma AR, Bhattacharya M, Sharma G, Lee S-S, Chakraborty C (2020) Tocilizumab: a therapeutic option for the treatment of cytokine storm syndrome in COVID-19. Arch Med Res. https:// doi.org/10.1016/j.arcmed.2020.05.009

Schoof M, Faust B, Saunders RA, Sangwan S, Rezelj V, Hoppe N, Deshpande I (2020) An ultra-high affinity synthetic nanobody blocks SARS-CoV-2 infection by locking spike into an inactive conformation. bioRxiv. https://doi.org/10.1101/2020.08.08.238469

Seo G, Lee G, Kim MJ, Baek S-H, Choi M, Ku KB, Lee C-S, Jun S, Park D, Kim HG, Kim S-J, Lee J-O, Kim BT, Changkyun Park E, Kim SI (2020) Rapid detection of COVID-19 causative virus (SARS-CoV-2) in human nasopharyngeal swab specimens using field-effect transistor-based biosensor. ACS Nano 14(4):51355142. https://doi.org/10.1021/acsnano.0c02823

Shannon A, Le NTT, Selisko B, Eydoux C, Alvarez K, Guillemot J-C, Canard B (2020) Remdesivir and SARS-CoV-2: structural requirements at both nsp12 rdrp and nsp14 exonuclease activesites. Antivir Res. https://doi.org/10.1016/j.antiviral.2020.10479 3

Sheahan TP, Sims AC, Zhou S, Graham RL, Pruijssers AJ, Agostini ML, Stevens LJ (2020) An orally bioavailable broad-spectrum

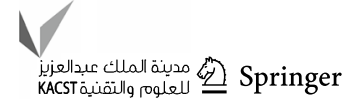


antiviral inhibits SARS-CoV-2 in human airway epithelial cell cultures and multiple coronaviruses in mice. Sci Trans Med. https ://doi.org/10.1126/scitranslmed.abb5883

Shereen MA, Khan S, Kazmi A, Bashir N, Siddique R (2020) COVID-19 infection: Origin, transmission, and characteristics of human coronaviruses. J Adv Res. https://doi.org/10.1016/j. jare.2020.03.005

Shin MD, Shukla S, Chung YH, Beiss V, Chan SK, Ortega-Rivera OA, Pokorski JK (2020) COVID-19 vaccine development and a potential nanomaterial path forward. Nat Nanotechnol. https:// doi.org/10.1038/s41565-020-0737-y

Silveira MAD, Teles F, Berretta AA, Sanches TR, Rodrigues CE, Seguro AC, Andrade L (2019) Effects of Brazilian green propolis on proteinuria and renal function in patients with chronic kidney disease: a randomized, double-blind, placebo-controlled trial. BMC Nephrol 25(1):140. https://doi.org/10.1186/s12882-019-1337-7

Sivaraman D, Pradeep P (2020) Revealing anti-viral potential of bioactive therapeutics targeting SARS-CoV-2-polymerase ( $\mathrm{rdrp}$ ) in combating COVID-19: molecular investigation on Indian traditional medicines. Preprints. https://doi.org/10.20944/preprints2 02003.0450.v1

Sportelli MC, Izzi M, Kukushkina EA, Hossain SI, Picca RA, Ditaranto N, Cioffi N (2020) Can nanotechnology and materials science help the fight against SARS-CoV-2? Nanomaterials 10(4):802. https://doi.org/10.3390/nano10040802

Staroverov SA, Vidyasheva IV, Gabalov KP, Vasilenko OA, Laskavyi VN, Dykman LA (2011) Immunostimulatory effect of gold nanoparticles conjugated with transmissible gastroenteritis virus. Bull Exp Biol Med 151(4):436. https://doi.org/10.1007/s1051 7-011-1350-8

Sun N, Wong W-L, Guo J (2020a) Prediction of potential 3clpro-targeting anti-SARS-CoV-2 compounds from Chinese medicine. Preprints. https://doi.org/10.20944/preprints202003.0247.v1

Sun X, Wang T, Cai D, Hu Z, Liao H, Zhi L, Wang J (2020b) Cytokine storm intervention in the early stages of COVID-19 pneumonia. Cytokine Growth Factor Rev. https://doi.org/10.1016/j.cytog fr.2020.04.002

Tu Y-F, Chien C-S, Yarmishyn AA, Lin Y-Y, Lu Y-H, Lin Y-T, Yang Y-P (2020) A review of SARS-CoV-2 and the ongoing clinical trials. Int J Mol Sci 21(7):2657. https://doi.org/10.3390/ijms2 1072657

van Doremalen N, Bushmaker T, Morris DH, Holbrook MG, Gamble A, Williamson BN, Tamin A, Harcourt JL, Thornburg NJ, Gerber SI, Lloyd-Smith JO, de Wit E, Munster VJ (2020) Aerosol and surface stability of SARS-CoV-2 as compared with SARS-CoV-1. New Engl J Med 382(16):1564-1567. https://doi. org/10.1056/NEJMc2004973

Villar J, Ferrando C, Martínez D, Ambrós A, Muñoz T, Soler JA, Conesa LA (2020) Dexamethasone treatment for the acute respiratory distress syndrome: a multicentre, randomised controlled trial. Lancet Respir Med 8(3):267-276. https://doi.org/10.1016/ S2213-2600(19)30417-5

Wang M, Cao R, Zhang L (2020) Remdesivir and chloroquine effectively inhibit the recently emerged novel coronavirus (2019 ncov) in vitro. Cell Res. https://doi.org/10.1038/s41422-020-0282-0

Wang Y, Zhang L, Sang L, Ye F, Ruan S, Zhong B, Song T, Alshukairi AN, Chen R, Zhang Z, Gan M, Zhu A, Huang Y, Luo L, Mok CKP, Al Gethamy MM, Tan H, Li Z, Huang X, Li F, Sun J, Zhang Y, Wen L, Li Y, Chen Z, Zhuang Z, Zhuo J, Chen C, Kuang L, Wang J, Lv H, Jiang Y, Li M, Lin Y, Deng Y, Tang L, Liang J, Huang J, Perlman S, Zhong N, Zhao J, Malik Peiris JS, Li Y, Zhao J (2020) Kinetics of viral load and antibody response in relation to COVID-19 severity. J Clin Invest 130(10):52355244. https://doi.org/10.1172/JCI138759

Weiss C, Carriere M, Fusco L, Capua I, Regla-Nava JA, Pasquali M, Mattevi C (2020) Toward nanotechnology-enabled approaches against the COVID-19 pandemic. ACS Nano. https://doi. org/10.1021/acsnano.0c03697

Weston S, Coleman CM, Sisk JM, Haupt R, Logue J, Matthews K, Frieman MB (2020) Broad anti-coronaviral activity of FDA approved drugs against SARS-CoV-2 in vitro and SARS-CoV in vivo. bioRxiv. https://doi.org/10.1101/2020.03.25.008482

WHO Solidarity trial consortium (2020) Repurposed antiviral drugs for COVID-19-interim WHO SOLIDARITY trial results. medRxiv preprint. https://doi.org/10.1101/2020.10.15.20209 817

WHO React. Rapid Evidence Appraisal for COVID-19 Therapies (REACT) Working Group (2020) Association between administration of systemic corticosteroids and mortality among critically Ill patients with COVID-19 a meta-analysis. JAMA. https ///doi.org/10.1001/jama.2020.17023

WHO. (2020). Novel coronavirus in house assay: summary of protocols. https://www.who.int/docs/default-source/coronaviruse/ whoinhouseassays.pdf. Accessed 11 Nov 2020

Williamson G, Kerimi A (2020) Testing of natural products in clinical trials targeting the sars-cov-2 (COVID-19) viral spike protein-angiotensin converting enzyme-2 (ACE2) interaction. Biochem Pharmacol. https://doi.org/10.1016/j.bcp.2020.114123

Wu SC (2020) Progress and concept for COVID-19 vaccine development. Biotechnol J 15(6):e2000147. https://doi.org/10.1002/ biot. 202000147

Yang R, Liu H, Bai C, Wang Y, Zhang X, Guo R, Chang H (2020) Chemical composition and pharmacological mechanism of qingfei paidu decoction and ma xing shi gan decoction against coronavirus disease 2019 (COVID-19): in silico and experimental study. Pharmacol Res. https://doi.org/10.1016/j. phrs.2020.104820

Yuan K, Yi L, Chen J, Qu X, Qing T, Rao X, Nie Y (2004) Suppression of SARS-CoV entry by peptides corresponding to heptad regions on spike glycoprotein. Biochem Biophys Res 319(3):746-752. https://doi.org/10.1016/j.bbrc.2004.05.046

Zahedipour F, Hosseini SA, Sathyapalan T, Majeed M, Jamialahmadi T, Al-Rasadi K, Sahebkar A (2020) Potential effects of curcumin in the treatment of COVID-19 infection. Phytother Res. https://doi.org/10.1002/ptr.6738

Zhao R, Li M, Song H, Chen J, Ren W, Feng Y, Gao GF, Song J, Peng Y, Su B, Guo X, Wang Y, Chen J, Li J, Sun H, Bai Z, Cao W, Zhu J, Zhang Q, Sun Y, Sun S, Mao X, Su J, Chen X, He A, Gao W, Jin R, Jiang Y, Sun L (2000) Early detection of SARSCoV-2 antibodies in COVID-19 patients as a serologic marker of infection. Clin Infect Dis 1:ciaa523. https://doi.org/10.1093/ $\mathrm{cid} / \mathrm{ciaa} 523$

Zhang N, Li C, Hu Y, Li K, Liang J, Wang L, Jiang S (2020a) Current development of COVID-19 diagnostics, vaccines and therapeutics. Microb Infect. https://doi.org/10.1016/j.micin f.2020.05.00

Zhang Q, Honko A, Zhou J, Gong H, Downs SN, Vasquez JH, Zhang L (2020b) Cellular nanosponges inhibit sars-cov-2 infectivity. Nano lett 20(7):5570-5574. https://doi.org/10.1021/acs.nanol ett.0c02278

Zhou P, Yang X-L, Wang X-G, Hu B, Zhang L, Zhang W, Huang C-L (2020a) A pneumonia outbreak associated with a new coronavirus of probable bat origin. Nature 579(7798):270-273. https:// doi.org/10.1038/s41586-020-2012-7

Zhou Y, Wang F, Tang J, Nussinov R, Cheng F (2020b) Artificial intelligence in COVID-19 drug repurposing. Lancet Digital Health. https://doi.org/10.1016/S2589-7500(20)30192-8

Zhu F-C, Guan X-H, Li Y-H, Huang J-Y, Jiang T, Hou L-H, Wang W-J (2020a) Immunogenicity and safety of a recombinant adenovirus type-5-vectored covid-19 vaccine in healthy adults aged 18 years or older: A randomised, double-blind, placebo-controlled, phase 2 trial. Lancet. https://doi.org/10.1016/S0140-6736(20)31605-6 
Zhu N, Zhang D, Wang W, Li X, Yang B, Song J, Lu R (2020b) A novel coronavirus from patients with pneumonia in china, 2019. N Engl J Med. https://doi.org/10.1056/NEJMoa2001017

Zhu Z, Lu Z, Xu T, Chen C, Yang G, Zha T, Xue Y (2020c) Arbidol monotherapy is superior to lopinavir/ritonavir in treating COVID-19. J Infect 81(1):e21-e23. https://doi.org/10.1016/j. jinf.2020.03.060
Ziegler CG, Allon SJ, Nyquist SK, Mbano IM, Miao VN, Tzouanas $\mathrm{CN}$, Hauser BM (2020) SARS-CoV-2 receptor ACE2 is an interferon-stimulated gene in human airway epithelial cells and is detected in specific cell subsets across tissues. Cell. https://doi. org/10.1016/j.cell.2020.04.035 